\title{
Neural Substrates of the Interplay between Cognitive Loading and Emotional Involvement in Bilingual Decision Making
}

\author{
Linyan Liu ${ }^{\mathrm{a}, \mathrm{b}}$, Francesco Margonic, Yuying He ${ }^{\mathrm{a}, \mathrm{b}}$, Huanhuan Liu ${ }^{\mathrm{a}, \mathrm{b}}$ \\ ${ }^{a}$ Research Center of Brain and Cognitive Neuroscience, Liaoning Normal University, \\ China. \\ ${ }^{\mathrm{b}}$ Key Laboratory of Brain and Cognitive Neuroscience, Liaoning Province, China. \\ ${ }^{\mathrm{c}}$ Department of Psychology and Cognitive Sciences, University of Trento, Italy.
}

\begin{abstract}
Author Note
This research was supported by a Grant from National Natural Science Foundation of China Youth Fund (31700991) and China Postdoctoral Science Foundation (2017M621158).

Correspondence concerning this article should be addressed to Huanhuan Liu, Research Center of Brain and Cognitive Neuroscience, Liaoning Normal University, Dalian, 116029, China. Telephone: 0411-8215-9733 Email: abcde69503@ 126.com
\end{abstract}




\begin{abstract}
Prior work investigated how foreign language impacts decision making by either reducing access to emotion or imposing additional cognitive demands. In this fMRI study, we employed a cross-task design to assess at the neural level whether and how the interaction between cognitive loading and emotional involvement is affected by language (native L1 vs. foreign L2). Participants completed a Lexico-semantic task where in each trial they were presented with either a neutrally or a negatively valenced word either in L1 or L2, and either under cognitive loading or not. After each trial, they had to decide whether to take a risky decision within a gambling game. During the Gamling task, left amygdala and right insula were more activated after having processed a negative word under cognitive loading. However, this was true for L1 but not for L2, suggesting that cognitive loading was germane and facilitated rather than hindered access to emotion only in L1. Further suggesting that cognitive load can enhance emotional sensitivity in L1 but not in L2, we found that functional connectivity between reward-related striatum and right insula increased under cognitive loading only in L1. Overall, results suggest that cognitive loading in L1 can favor access to emotion and lead to a more impulsive decision making, whereas cognitive loading in L2 can attenuate access to emotion and lead to a more rational decision making.

Keywords: foreign language effect, cognitive load, emotional involvement, amygdala, insula.
\end{abstract}




\section{Neural Substrates of the Interplay between Cognitive Loading and Emotional Involvement in Bilingual Decision Making}

Facing a decision making task, bilinguals are often less impulsive and more analytic if the information is presented in their second language (L2) rather than in their native language (L1), an effect that was termed foreign language effect (Caldwell-Harris, 2015; Costa et al., 2014, 2017; Geipel et al., 2015; Hayakawa et al., 2016, 2017; Keysar et al., 2012; Montero-Melis et al., 2020). For instance, foreign language may reduce or eliminate decision making biases such as the framing effect (Keysar et al., 2012), the aversion to losses (Costa et al., 2014), and the hot hand fallacy (Gao et al., 2015).

Foreign language effect can be attributed to the fact that L2 is less grounded in the emotional system compared to L1 (Dylman \& Bjarta, 2018; Kuhne \& Gianelli, 2019; Sulpizio et al., 2019). Messages processed in L2 overall elicit milder emotional arousal than messages processed in L1, which in turn may lead to a more careful and rational decision making (Díaz-Lago \& Matute, 2019; Hadjichristidis et al., 2018; Keysar et al., 2012).

Another key factor can be that making decisions in L2 rather than L1 involves greater cognitive resources (Korn et al., 2019; Oganian et al., 2016). Indeed, orthography, phonetic, semantic and grammatical processing in L2 requires additional cognitive resources due to lower proficiency (Hasegawa et al., 2002; Stiller \& Schworm, 2019). The less automatic and more difficult processing in L2 may thus be source for distancing and lead to a more deliberate and analytic decision making. 
As of yet, however, emotional involvement and cognitive loading were often treated as two separate factors, and prior work did not systematically investigate the underlying interaction between them in the context of the foreign language effect. Since cognitive resources are limited (Franconeri et al., 2013; Lieder \& Griffiths, 2019; Vroomen et al., 2001), the more they are recruited for orthography and semantic processing, the less they can be used for emotional processing. Despite this, cognitive load does not always hinder emotional processing (Berggren et al., 2012; Debue \& van de Leemput, 2014).

Cognitive Load Theory argues that font emphasis, for instance, can reduce the extraneous cognitive loading related to the presentation of materials and improve the germane cognitive loading which is functional to the learning process (Paas \& Sweller, 2014; Schneider et al., 2018). Therefore, a greater allocation of cognitive resources can sometimes, when germane, work alongside an enhanced processing of the emotional information in the lexico-semantic access. However, this is more likely to happen in L1 than in L2. Indeed, because of the additional cognitive resources needed to process written or spoken foreign language, it is less likely to find germane cognitive loading in L2. Accordingly, cognitive loading may promote or hinder emotional processing depending also on the language in which the message is presented.

\section{Neural Bases of the Foreign Language Effect}

Two brain regions have been shown to be crucially associated with emotional involvement: insula, which works for detecting emotion (Pedale et al., 2019; Simmons et al., 2012; Thom et al., 2012), and amygdala, which is implicated in inducing the emotional response (Dehdar et al., 2019; Guex et al., 2019; Janak \& Tye, 2015; 
Méndez-Bértolo et al., 2016; Namburi et al., 2015; Phan et al., 2004; Tye et al., 2011).

In L2, activation of insula and amygdala may be reduced under cognitive loading. This can be so because, given the weakness of the semantic access to orthography/phonology in L2 (Green, 1998; Runnqvist et al., 2019), a competition for resource allocation may arise between the semantic and the emotional access. In contrast, in L1, bilinguals need to recruit less cognitive resources to process the language, and thus germane loading likely triggers a more indepth processing of the emotional content (Dylman \& Bjärtå, 2018; Pavlenko, 2012; Ponari et al., 2015). Different lexical—semantic activation thresholds may thus lead to different emotional experiences: cognitive loading may deepen the emotional experience if the message is presented in L1 but weaken it if the message is presented in L2.

A fMRI study did indeed reveal that cognitive load can influence the emotional processing in L1 (Van Dillen et al., 2009). Participants saw a negative or neutral picture, performed an arithmetic task, and then rated the perceived unpleasantness of the picture. The task load was shown to down-regulate the amygdala and right insula activity for negative stimuli, resulting in a reduction of the negative emotions.

Relevant is also a fMRI study in which the role of emotional involvement in bilinguals' decision making was assessed (Zheng et al., 2020). Participants made 'play' or 'leave' decisions in an equal-odds Gambling task where gambling feedbacks were presented in either L1 or L2. At the behavioral level, both in L1 and L2 participants showed the Gambler's fallacy, i.e. the tendency to bet more when losing rather than winning. However, the fMRI scanning revealed that language modulated the neural 
responses associated to the gambling feedbacks and to the participants' decisions. Importantly, the activation of the reward brain networks in response to positive feedbacks was exaggerated in L2 compared to L1.

Authors thus found that receiving a positive message in L2 amplified the associated emotion. This evidence is somehow in contrast with the emotion-reducing hypothesis according to which L2 reduces the emotional reactions, but it is consistent with the positive-bias hypothesis according to which L2 specifically enhances positive emotions (Caldwell-Harris, 2015; Sheikh \& Titone, 2016). In general, Zheng et al. (2020)'s work is relevant as it provides evidence of a foreign language effect on people's economic decisions at the neural level. However, it remains an open question whether and how the neural networks associated with emotional processing are differently regulated by cognitive loading depending on the language (L1 vs. L2).

\section{This Study}

The current study employed functional magnetic resonance imaging (fMRI) to characterize the neural activation underpinning the interaction between cognitive load and emotional involvement in the foreign versus native language context. Participants were first presented with a Lexico-semantic task widely used in semantics research (Fujimaki et al., 2009; Hinojosa et al., 2010; Pu et al., 2005). In each trial they were presented with either a neutrally or a negatively valenced word either in L1 or in L2, and either under cognitive loading or not. Three factors were thus varied in this task: language (L1, L2), emotion (valenced, not valenced), cognitive load (low, high). 
We aimed at assessing the influence of these three factors and their interaction on participants' subsequent decisions in an even-probability Gambling task (Gao et al., 2015; Zheng et al., 2019). Moreover, we aimed at revealing the associated neural activity. We predicted coordination or competition varying across languages and cognitive load conditions between the dorsal striatum, which is associated with decision making (Korucuoglu et al., 2020; Sharpe et al., 2019; Wimmer et al., 2014), and insula and amygdala (Gorka et al., 2019; Korgaonkar et al., 2019; Shiv et al., 2005), two areas associated with emotion processing. If the automaticity of L1 processing enables more emotional access whereas the increased cognitive demands in L2 leave little room for emotionality, we should find that cognitive loading boosts access to emotion in L1 but hinders access to emotion in L2.

\section{Methods}

\section{Participants}

Thirty unbalanced Chinese-English (L1-L2) bilinguals participated in this study. They were right handed with normal or corrected-to-normal vision and no history of neurological or psychological impairments. None of them were receiving treatment with psychoactive medication. Due to the excessive head movement of five participants, the imaging data analysis included only 25 participants ( 9 male, $M=22.56 \pm 2.35$ years). The behavioral data analysis included 28 participants ( 10 male, $M=22.61 \pm 2.27$ years $)$ because the answers of two participants in the Gambling task were extreme (gambling ratio $>85 \%$ ). The research protocol was approved by the Institutional Review Board at the School of Psychology, Liaoning Normal University. 
Participants' language proficiency was assessed through questionnaires asking the age of L2 acquisition and to self-rate the language skills on a scale that ranged from 1 (= no knowledge of $L 1 / L 2)$ to 6 (= perfect knowledge). Language proficiency was also measured with the Oxford Placement Test (OPT; Allan, 2004), by administering 25 multiple choice questions and a cloze test. Maximum score was 50 (see Appendix A). Table 1 shows participants' average language proficiency. Four paired t-test revealed that proficiency ratings were significantly higher for L1 than L2 in listening, speaking, reading and writing, $t(29) \geq 4.75, p s<0.001$. Moreover, self-rating and OPT scores were similar to those of Chinese-English bilinguals with intermediate L2 proficiency who participated in prior research (Liang \& Chen, 2014; Liu et al., 2016). At the end of the session, participants completed a Risk Attitude Scale ranging from 1 (= conservative) to 5 (= adventure), $M=2.81, S D=0.60$ (Weber et al., 2002; Appendix B).

\section{Table 1}

Participants' Characteristics (Mean $\pm S D)$.

\begin{tabular}{|c|c|c|c|c|}
\hline & \multicolumn{2}{|c|}{ Behavioral data $(N=28)$} & \multicolumn{2}{|c|}{ fMRI data $(N=25)$} \\
\hline & L1 & L2 & $\mathrm{L} 1$ & $\mathrm{~L} 2$ \\
\hline AoA & ---- & $9.32 \pm 2.07$ & ---- & $9.28 \pm 2.19$ \\
\hline Listening & $5.32 \pm 0.72$ & $3.50 \pm 1.17$ & $5.28 \pm 0.74$ & $3.52 \pm 1.22$ \\
\hline Speaking & $4.86 \pm 0.71$ & $3.46 \pm 0.88$ & $4.80 \pm 0.71$ & $3.44 \pm 0.92$ \\
\hline Reading & $4.36 \pm 1.13$ & $3.00 \pm 1.20$ & $4.32 \pm 1.14$ & $3.04 \pm 1.27$ \\
\hline Writing & $4.82 \pm 0.72$ & $3.25 \pm 1.38$ & $4.80 \pm 0.71$ & $3.16 \pm 1.43$ \\
\hline OPT & & $34.5 \pm 6.04$ & & $34.0 \pm 6.18$ \\
\hline
\end{tabular}

Note: AoA means Age of Acquisition of L2; OPT stands for Oxford Placement Test. 


\section{Materials}

The Lexico-semantic task (Fujimaki et al., 2009; Hinojosa et al., 2010; Nakamura et al., 2020; Pauligk et al., 2019; Pu et al., 2005) included 79 Chinese words (42 negative, 37 neutral) translated into English by using the Oxford Advanced EnglishChinese Dictionary (Appendix C). Words had two characters in Chinese and four to nine letters in English, $M=5.80 \pm 1.33$. Their emotional valence was established by using the modern Chinese words emotion rating scale (Wang et al., 2008).

Forty words (20 negative, 20 neutral) in simplified L1 (e.g. 恐惧, 新闻) and lowercase L2 (e.g. fear, news) were chosen for the Low-load condition. Forty words in traditional L1 (e.g. 恐懼，新聞) and capital L2 (e.g. FEAR, NEWS) were instead chosen for the High-load condition. Words in the two conditions were phonologically and semantically identical but written in a different form (see Figure 1a).

Words in L1 and L2 were matched for lexical frequency and emotional valence (Cai \& Brysbaert, 2010; see Table 2). Both negative and neutral words did not have a different lexical frequency in the two languages, $t(19) \leq 0.63, p s \geq 0.536$, nor in both L1 and L2 neutral words had different frequency than negative words, $t(19) \leq 1.99$, ps $\geq 0.060$. To assess the emotional valence, 20 unbalanced Chinese-English bilinguals completed the emotional valence questionnaire rating words from 1 (= extremely positive) to 5 (= very negative). For both $\mathrm{L} 1$ and $\mathrm{L} 2$, negative and neutral words had a different valence, $t(19) \geq 12.87, p s<0.001$, whereas L1 and L2 negative words, as well as L1 and L2 neutral words, showed no such difference, $t(19) \leq 1.50, p s \geq 0.147$. 
In addition, 40 pseudo-words were used (20 Chinese, 20 English). Chinese pseudowords were constructed by changing a character of a Chinese word, making a corresponding pronounceable and orthographically legal pseudo-word (e.g. 打驾). English pseudo-words were instead constructed by randomly by substituting or adding one letter (e.g. flyy; see Figure 1a). Pseudo-words were not analyzed.

\section{Table 2}

Lexical Frequency (Occurrences per Million) and Emotional Valence of L1 and L2 Words (Mean $\pm S D)$.

\begin{tabular}{lccc}
\hline & & Lexical frequency & Emotional valence \\
\hline \multirow{2}{*}{ Negative } & L1 & $29.13 \pm 35.21$ & $3.17 \pm 0.21$ \\
& L2 & $37.57 \pm 69.87$ & $3.18 \pm 0.15$ \\
Neutral & L1 & $65.53 \pm 72.71$ & $2.46 \pm 0.21$ \\
& L2 & $68.87 \pm 64.28$ & $2.40 \pm 0.15$ \\
\hline
\end{tabular}

In the Lexico-semantic task, participants were presented with four blocks, each including 50 trails: 20 Chinese words, 5 Chinese pseudo-words, 20 English words, and 5 English pseudo-words. In total, participants thus read 200 words, 160 correct and 40 pseudo-words. After each trial, participants played in a Gambling task trial.

Materials used for the Gambling task were adapted from Gao et al. (2015). Participants received four blocks of 50 trials. Each block included 25 possible gambling options each randomly repeated twice. Options were 50/50 gambles made up from five gain values $(+100,+80,+60,+40,+20)$ paired with five loss values $(-50,-40,-30,-20$, -10). For each gamble, participants saw two numbers preceded by a sign indicating the 
prospective gain and loss (e.g. +100 and -50$)$. These numbers were separated by a horizontal bar indicating that the probability of winning or losing was 0.50 (see Figure 1b). In $76 \%$ of the trails the magnitude of prospective gain was larger compared to loss, in $16 \%$ was smaller, and in $8 \%$ of the trails was equal. A large magnitude of prospective gain was used in most of the trials to lead participants to gamble more often than not.

\section{Procedure}

In our cross-task study, participants were first presented with a practice block of 26 trials that helped them to understand the instructions. Participants were then presented with 200 trials, equally divided into four blocks, with two practice trials per block. L1 and L2 words were randomly mixed and presented in the four blocks. The order of blocks was counterbalanced across participants. Stimuli were white words or numbers presented on a black background using E-Prime 2.0 software on a Dell PC. Words and numbers were displayed in Courier New, words in size 34 and numbers in size 18.

In the Lexico-semantic task, participants' attention was directed to the lexicosemantic properties of the words by asking them to distinguish meaningful words from pseudowords. Each trial started with a fixation cross displayed for $500 \mathrm{~ms}$, followed by a word displayed for $3000 \mathrm{~ms}$ to allow semantic processing (see Figure 1c). Participants had to judge, as quickly and accurate as possible, whether the word was correct by pressing $1(=y e s)$ or $3(=n o)$. Key buttons were counterbalanced across participants.

After each Lexico-sematic trial, participants received a Gambling task trial which started with a fixation cross displayed for $500 \mathrm{~ms}$ followed by a $50 / 50$ gamble option (Figure 1b). Participants had to decide within $3000 \mathrm{~ms}$ whether to bet by pressing 1 (= 
play) or not to bet by pressing 3 (= leave). Key buttons were counterbalanced across participants. If participants chose to leave or did not press any buttons, a blank screen appeared for $1000 \mathrm{~ms}$, and the next trial started after another blank screen displayed for a random duration between 500 and $2000 \mathrm{~ms}$. If participants chose to gamble, a feedback appeared for $1000 \mathrm{~ms}$ displaying the sum earned or lost in the trial. This outcome was randomly generated where each option was given $50 \%$ probability. Lastly, a blank screen was displayed for a 500-2000 ms time window. 
a.

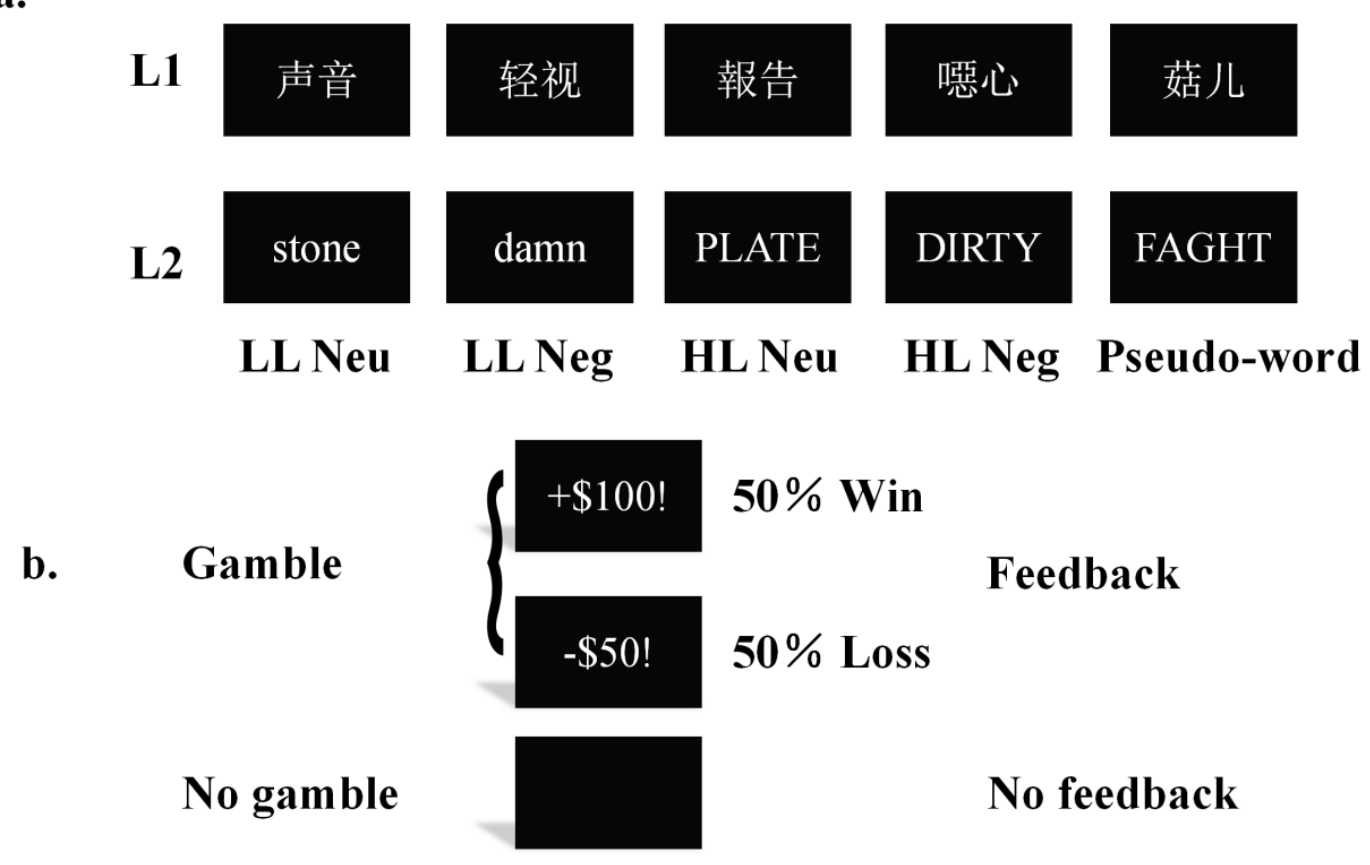

c.

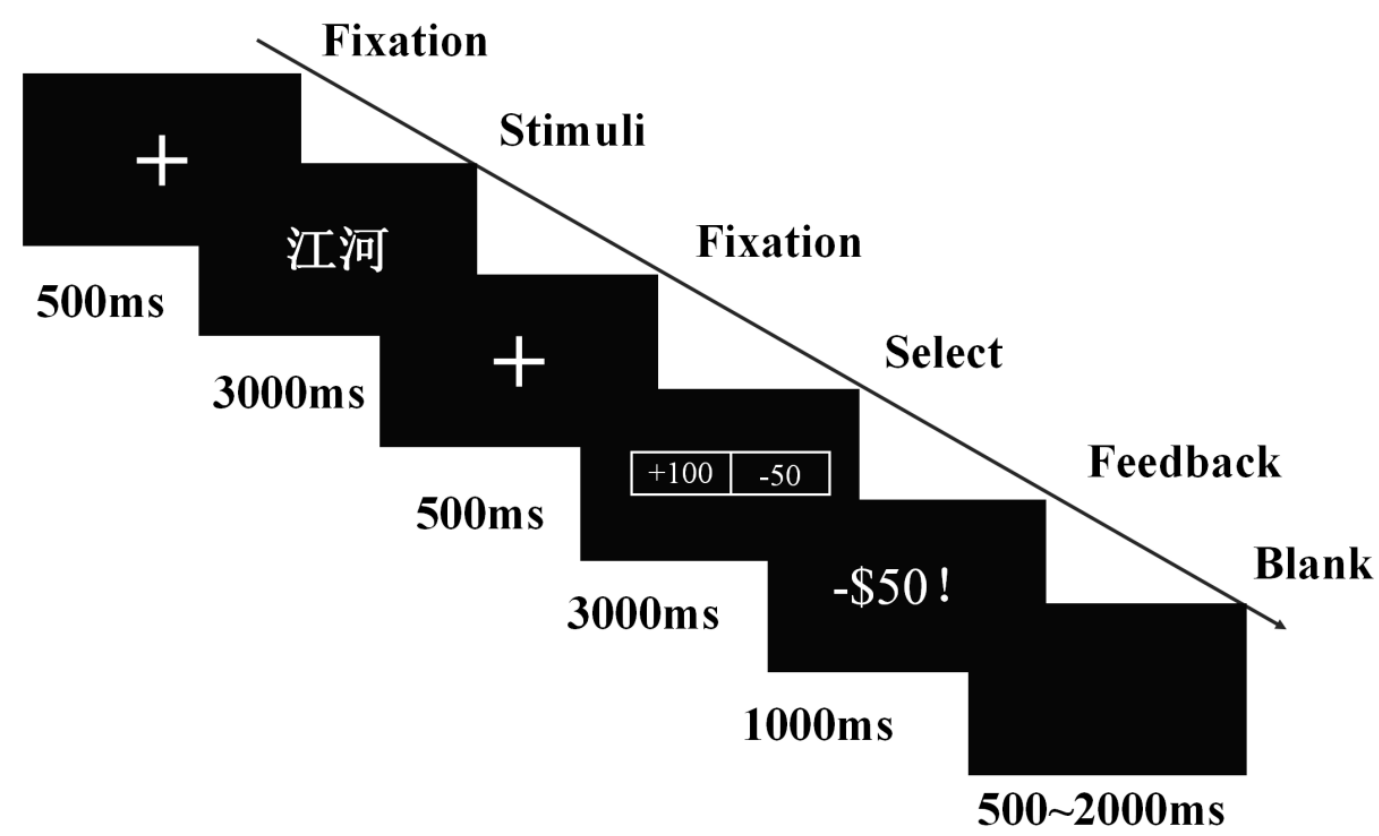

Figure 1. (a) In the Lexico-semantic task, participants were presented with words combined for L1 and L2 into four clusters: LL Neu (Low-Load Neutral), LL Neg (LowLoad Negative), HL Neu (High-Load Neutral), HL Neg (High-Load Negative). (b) In the Gambling task, if participants chose to bet, they saw either the sum earned or lost, whereas if they did not gamble, a black screen appeared. (c) Design and timing of the 
cross-task experiment, including a Lexico-semantic task followed by a Gambling task.

\section{fMRI Data Acquisition}

Functional and structural images were acquired with a GE Discovery MR750 3T scanner. Participant's head was secured to minimize movement during scanning. Functional scans were obtained using a T2*-weighted gradient echo planar imaging (EPI) sequence. The following scan parameters for functional images were used: slice thickness $=2 \mathrm{~mm}$; sequential acquisition $=33$ axial slices; repetition time $(\mathrm{TR})=2000$ $\mathrm{ms}$; echo time $(\mathrm{TE})=30 \mathrm{~ms}$; flip angle $=90^{\circ}$; image matrix $=64 \times 64$; field of view $($ FOV $)=224 \times 224 \mathrm{~mm}$; voxel size $=3.5 \times 3.5 \times 4.2 \mathrm{~mm}$. For a total of four blocks, functional scanning session contained 248, 245, 241 and 243 time points. Structural images were collected using a T1-weithted 3-D MPRAGE sequence to co-register with the functional images $\left(\mathrm{TR}=6.652 \mathrm{~ms}, \mathrm{TE}=2.928 \mathrm{~ms}\right.$, flip angle $=12^{\circ}$, sequential acquisition $=192$ slices, slice thickness $=1 \mathrm{~mm}$, spacing between slices $=1 \mathrm{~mm}$, image matrix $=256 \times 256, \mathrm{FOV}=256 \times 256 \mathrm{~mm}$, voxel size $=1 \times 1 \times 1 \mathrm{~mm})$.

\section{Behavioral Data Analysis}

Both participants' accuracy (ACC) scores and reaction times (RT) in the Lexicosemantic task were analyzed with a generalized linear mixed effect model using language, cognitive load and emotional valence as fixed effects. Participants was added as the random effect in the ACC analysis, whereas participants and words were added as random effects in the RT analysis. Participants' decisions and RTs in the Gambling task were analyzed with a liner mixed effect model using the three factors listed above 
as fixed effects, and participants and potential gain/loss as random effects.

\section{fMRI Data Preprocessing}

fMRI data were preprocessed with DPABI (Yan et al., 2016). First, all the EPI DICOM data were converted to NIFTI format, and the first 15 volumes of each run were discarded because of T1 relaxation artifacts. Second, all volumes slice scan times were corrected to the middle time slice and realigned to the first scan to correct for head motion. Third, the structural images of each participant were co-registered with the mean functional images and next they were normalized to the Montreal Neurological Institute template. Fourth, all voxels were resampled to $3 \times 3 \times 3 \mathrm{~mm}$. Fifth, all functional volumes were smoothed by using a 6-mm FWHM isotropic Gaussian kernel.

\section{fMRI Data Analysis}

First-level statistical analysis was conducted using SPM12 software. General linear models were computed from the 100 z-normalized volume time courses (25 participants $\times 4$ blocks). The blood oxygen level-dependent (BOLD) response was modeled using a double gamma hemodynamic response function. A general linear model was performed for each of the four blocks. For the the Lexico-semantic task, factors were language, cognitive load and emotional valence. For the Gambling task, factors were language, cognitive load, emotional valence and choice (gamble, no gamble).

We ran a full factorial analysis on the Lexico-semantic task and Gambling task data to test for main effects and interactions with one-way, two-way or three-way ANOVAs. Region of Interest (ROI) analyses were done with MarsBaR tool, using percent signal change to explore the dynamic changes of activation over time in ROI. To understand 
the three-way interactions, we extracted the beta values of significant clusters by averaging over all voxels within a cluster. Post-hoc comparisons were performed on the extracted beta values.

Analyzing activation associated with decisions in the Gambling task, we found a two-way significant interaction between cognitive load and emotional valence in the right insula (Table 4). Thus, we assessed the cognitive load-dependent functional connectivity of the right insula with other regions using the PsychoPhysiological Interaction (PPI; Di et al., 2019; McLaren et al., 2012; O’Reilly et al., 2012).

We started by creating a seed region using a $3 \mathrm{~mm}$ diameter sphere in the right insula $(27,24,-15)$ activated for negative words compared to neutral words. At the first-level analysis, we used a standard context-dependent PPI (Stephan et al., 2003). We extracted the first mean time series within the right insula seed. We next created PPI regressor using element-by-element products of the extracted, deconvolved insula time series and a vector coding for the main effect of cognitive load (1 for High-load, 1 for Low-load). This product was reconvolved with the canonical hemodynamic response function and entered as PPI regressor along with the cognitive load (psychological), right insula time series (physiological) and the head motion (nuisance) regressors. Subject-specific PPI models were run, and contrast images were generated for High-load and Low-load PPIs. For cognitive load-dependent functional connectivity of the right insula with other regions in L2, the same operation was done.

\section{Results}

\section{Behavioral Results}




\section{Lexico-semantic Task}

Figure 2 displays average participants' accuracy (ACC) scores and reaction times (RTs) in the Lexico-semantic task. When analyzing RTs data, we focused only on the accurate responses, thus removing $12 \%$ of participants' answers.
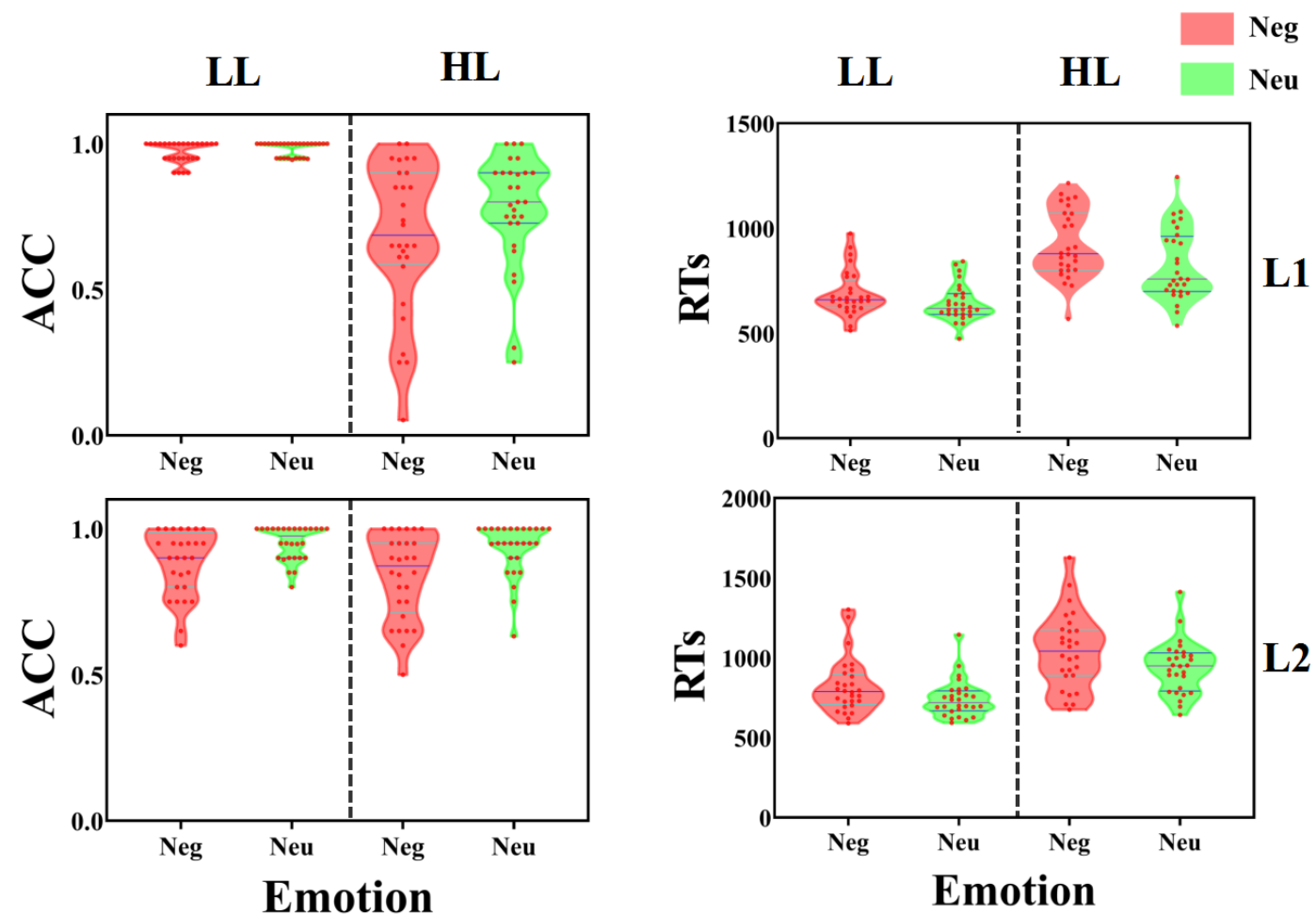

Figure 2. Accuracy scores (left) and reaction times (right) in the Lexico-semantic task split by language, cognitive load and emotional valence. Points represent participants' means, the middle line reflects the median, other lines represent the quartiles $(75 \%$ and 25\%). Note: $\mathrm{ACC}=$ Accuracy, RT $=$ Reaction time, $\mathrm{LL}=$ Low-load, HL $=$ High-load, Neg $=$ Negative, $\mathrm{Neu}=$ Neutral .

The analysis on ACC revealed significant main effects of language, $\beta=-1.55, z=$ $-5.40, p<0.001$, and cognitive load, $\beta=-2.89, z=-10.60, p<0.001$. Average accuracy was higher in L2 than in $\mathrm{L} 1(M=0.90 \pm 0.30$ and $M=0.85 \pm 0.35$, respectively $)$, and 
lower under cognitive loading $(M=0.81 \pm 0.39$ in High-load condition, $M=0.95 \pm$ 0.22 in Low-load condition). Crucially, there was a significant Language $\times$ Cognitive load interaction, $\beta=2.49, z=7.67, p<0.001$. Accuracy was lower under cognitive loading for L1 words $(M=0.73 \pm 0.44$ and $M=0.98 \pm 0.15)$, but this was true only to a lesser extent in $\mathrm{L} 2(M=0.89 \pm 0.32$ and $M=0.92 \pm 0.28)$.

The analysis on RTs relevaled significant main effects of language, $\beta=126.45, z=$ 3.82, $p=0.001$, and cognitive load, $\beta=236.10, z=6.97, p=.001$. RTs in L1 condition were shorter than those in L2 $(M=745 \pm 294 \mathrm{~ms}$ and $M=872 \pm 353 \mathrm{~ms}$, respectively $)$, and longer under cognitive loading $(M=920 \pm 367 \mathrm{~ms}$ in High-load condition, $M=$ $717 \pm 265 \mathrm{~ms}$ in Low-load condition). There results suggest that cognitive loading had a similar effect on the processing in the two languages.

\section{Gambling Task}

Figure 3 displays the average proportion of participants who chose to bet (Gambling ratio) and their average reaction times (RTs) for each condition. Only participants' decisions made after an accurate judgment in the Lexico-semantic task were analyzed (12\% of the decisions were thus excluded). 

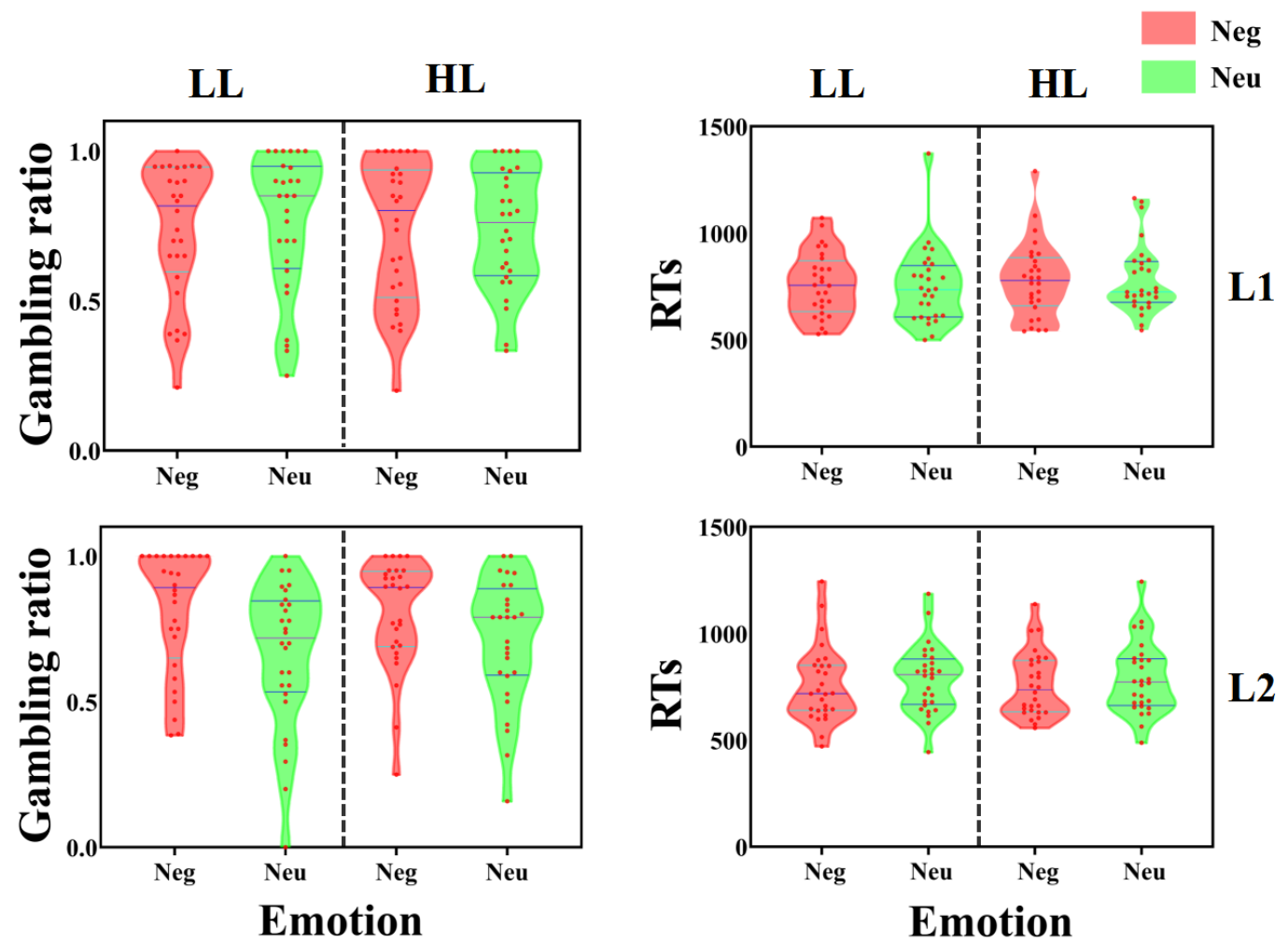

Figure 3. Gambling ratio (left) and reaction times (right) in the Gambling task split by language, cognitive load and emotional valence. Points represent participants' means, the middle line reflects the median, other lines represent the quartiles (75\% and 25\%). Note: $\mathrm{RT}=$ Reaction time, $\mathrm{LL}=$ Low-load, $\mathrm{HL}=$ High-load, Neg $=$ Negative, $\mathrm{Neu}=$ Neutral.

Participants gambled more as the potential gain increased, $\beta=0.06, p<.001$, and gambled less as the potential loss increased, $\beta=-0.07, p<.001$. They spent less time making decisions as the potential gain increased, $\beta=-15.94, p<.001$, and needed more time as the potential loss increased, $\beta=13.94, p<.001$. Instead, the generalized linear mixed effect model on gambling ratios and RTs, which was run to test the effect of the Lexico-semantic task on the Gambling task, did not reveal any significant effect (Appendix D). 


\section{fMRI Full Factorial Analysis Results}

The full factorial analysis revealed a significant Language $\times$ Cognitive load $\times$ Emotional valence interaction in the left amygdala and right insula (Figure 4). Thus, we chosen left amygdala and right insula as Regions of Interest (ROIs). These areas are known to be associated with emotion processing (Gorka et al., 2019; Korgaonkar et al., 2019; Shiv et al., 2005; Xue et al., 2011; Zhang et al., 2019).

\section{Lexico-semantic Task}

With respect to the right insula (BA47_R: 2724 -15), we found a main effect of language, $p=0.030$, with greater activity in L2 trials than in L1 trials $(M=-2.31, S D=$ 4.01, and $M=-3.17, S D=3.75$, respectively). No significant result was instead found with respect to the left amygdala (BA28_L: -27 3 -24).

\section{Gambling Task}

For the right insula (BA47_R: 2724 -15), the analysis revealed a significant interaction between cognitive load and emotional valence (see Table 3). The right insula was activated more under cognitive loading in the negative words condition, $p=$ 0.032, but this was not true in the neutral words condition. The significant Language $\times$ Cognitive load $\times$ Emotional valence interaction was primarily due to robust activation under cognitive loading in the L1 negative words condition, $p<0.007$, and an unexpected increased activation under cognitive loading in the L1 neutral words condition too, $p=0.003$ (see Table 4).

With respect to the left amygdala (BA28_L: -27 3 -24), the analysis revealed significant main effects of language, $p=0.032$, and cognitive load, $p=0.002$. This area 
was activated more in L1 than in $\mathrm{L} 2(M=0.07, S D=3.08$, and $M=-1.03, S D=3.56$, respectively), and more under cognitive loading $(M=0.22, S D=3.57$, and $M=-1.18$, $S D=3.01$; see Table 3). The analysis revealed also a significant Language $\times$ Emotional valence interaction: Left amygdala was activated more for L1 than for L2 in the negative words condition, $p=0.007$, but this was not true for the neutral words condition. Lastly, a significant Language $\times$ Cognitive load $\times$ Emotional valence interaction was primarily due to greater activation under cognitive loading for L1 negative words, $p<0.001$ (see Table 4).

In sum, we found greater activation of left amygdala under cognitive loading in L1 but not in L2, suggesting that germane cognitive loading in L1 favored an indepth emotion processing. By contrast, L2 may have hindered further processing because of the greater cognitive resources needed to process words in L2. Furthermore, under cognitive loading L1 negative words but not L1 neutral words activated the right insula, again suggesting that cognitive load interplays with emotion processing in L1. 


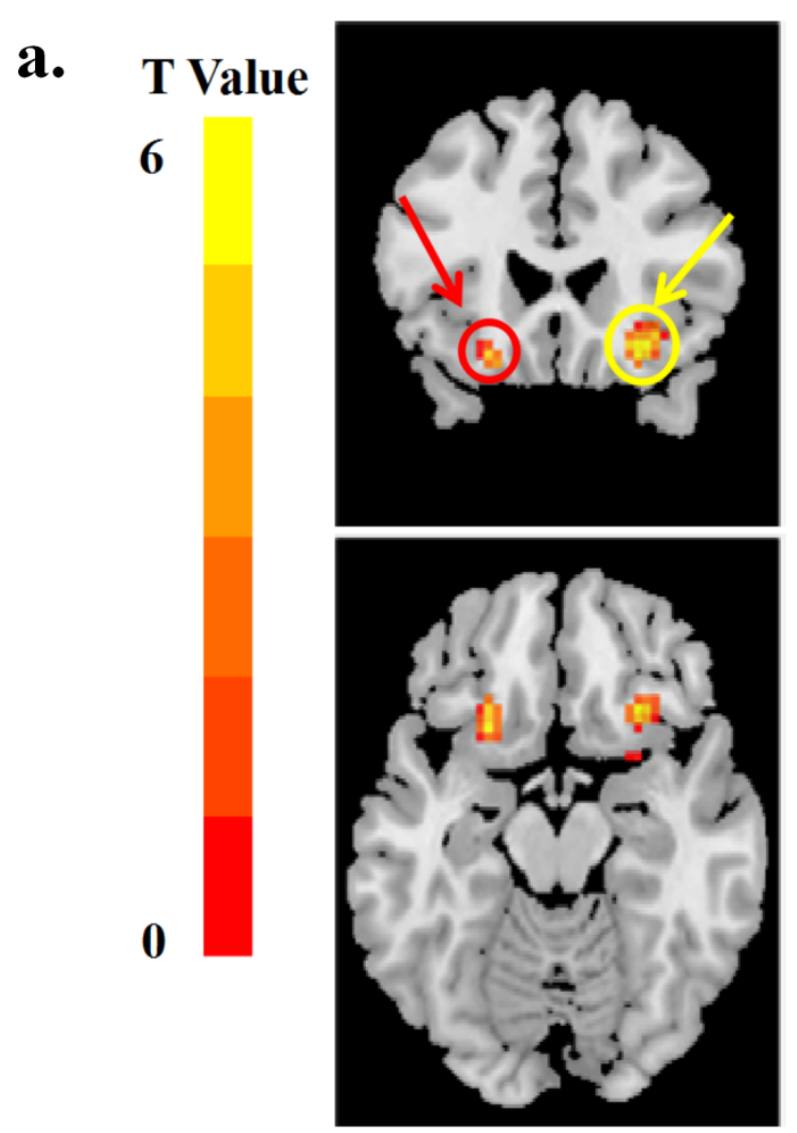

b.
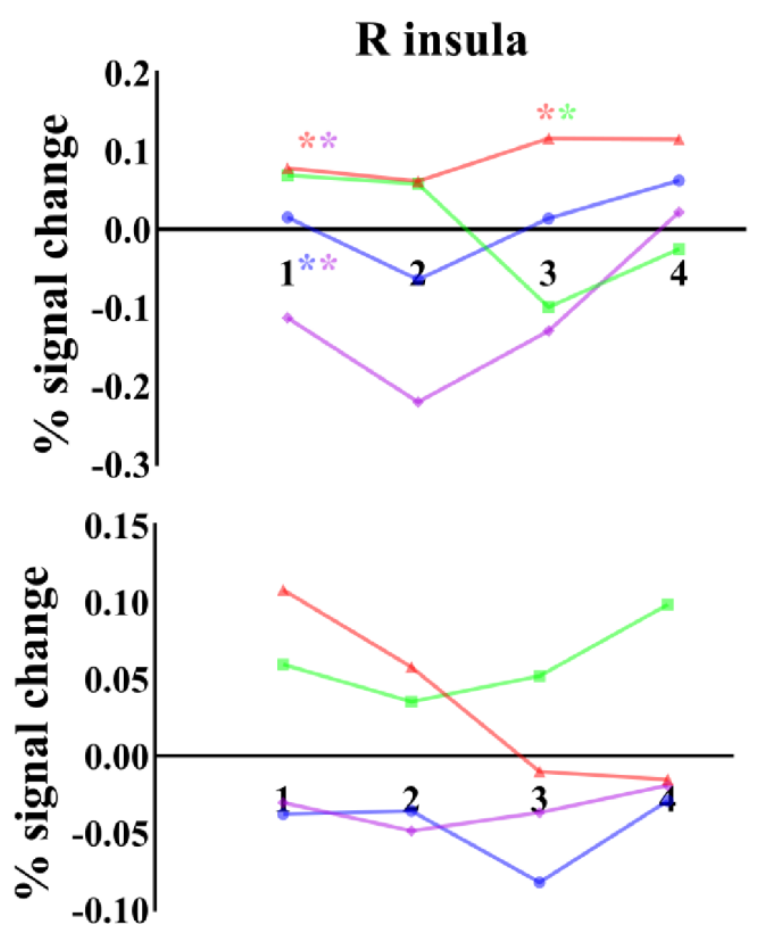

Time Bin
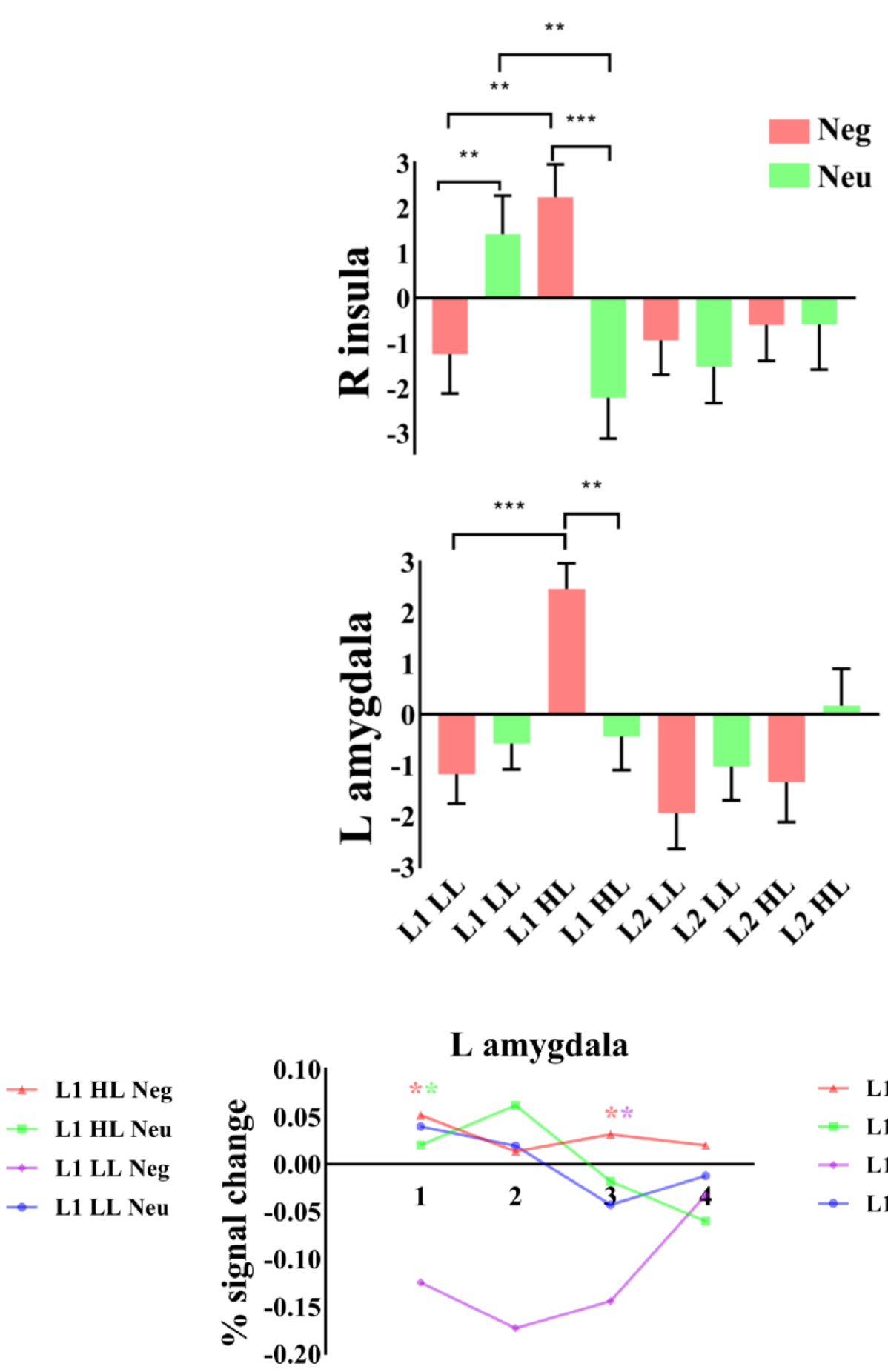

$\rightarrow$ L1 HL Neg

- L1 HL Neu

$\rightarrow$ L1 LL Neg

$\rightarrow$ L1 LL Neu

- L2 HL Neg
$+\quad$ L2 HL Neu
$+\quad$ L2 LL Neg
- L2 LL Neu

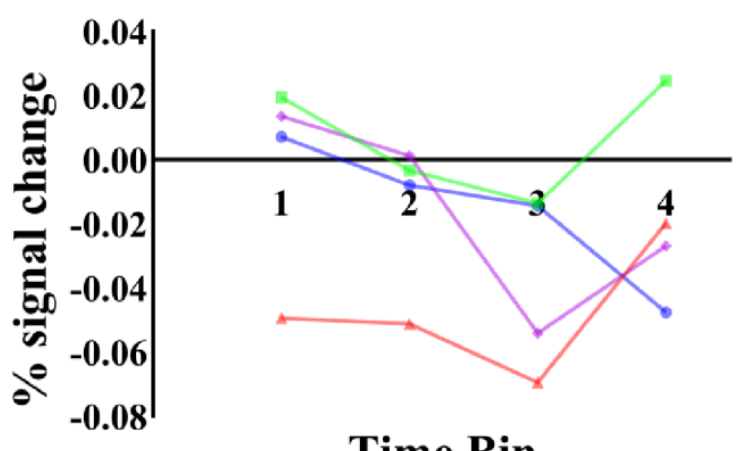

$\rightarrow$ L2 HL Neg

- L2 HL Neu

$\rightarrow$ L2 LL Neg

$\rightarrow$ L2 LL Neu

Time Bin 
Figure 4. Panel (a) displays the interaction between language, cognitive load and emotional valence in the right insula (yellow arrow) and left amygdala (red arrow) during the Gambling task (GRF correction, voxel $=.001$, cluster $=.05)$. The charts on the right show the beta values that were extracted from the left amygdala and right insula (radius $=3 \mathrm{~mm}$ ). Panel (b) displays the percent signal change in all the conditions for both L1 and L2 in right insula and left amygdala. The asterisks indicate significant pairwise differences between conditions (e.g. a red asterisk followed by a purple asterisk $* *$ indicates a significant difference between L1 HL Neg, red *, and L1 LL Neg, purple $*$ ). Note: LL = Low-load, HL = High-load, Neg = Negative, Neu = Neutral.

Table 3

Predictors of Right Insula and Left Amygdala Activation during the Gambling Task.

\begin{tabular}{lcccccc}
\hline & \multicolumn{3}{c}{ Right insula } & \multicolumn{3}{c}{ Left amygdala } \\
\cline { 2 - 7 } & $F$ & $p$ & $\eta^{2}$ & $F$ & $p$. & $\eta^{2}$ \\
\hline Language & 2.10 & 0.161 & 0.084 & $\mathbf{5 . 2 4}$ & $\mathbf{0 . 0 3 2} *$ & $\mathbf{0 . 1 8 6}$ \\
Cognitive load & 0.23 & 0.636 & 0.010 & $\mathbf{1 1 . 7 6}$ & $\mathbf{0 . 0 0 2 * *}$ & $\mathbf{0 . 3 3 8}$ \\
Emotion & 1.92 & 0.179 & 0.077 & 0.01 & 0.927 & $<0.001$ \\
Language $\times$ Cognitive load & 0.46 & 0.505 & 0.020 & 1.55 & 0.225 & 0.063 \\
Language $\times$ Emotion & 0.35 & 0.560 & 0.015 & $\mathbf{5 . 5 2}$ & $\mathbf{0 . 0 2 8} *$ & $\mathbf{0 . 1 9 4}$ \\
Cognitive load $\times$ Emotion & $\mathbf{9 . 1 5}$ & $\mathbf{0 . 0 0 6 * *}$ & $\mathbf{0 . 2 8 4}$ & 4.00 & 0.058 & 0.148 \\
$\quad$ & & & & & & \\
Language $\times$ Cognitive load $\times$ & $\mathbf{1 5 . 7 8}$ & $\mathbf{0 . 0 0 1 * * *}$ & $\mathbf{0 . 4 0 7}$ & $\mathbf{1 2 . 7 2}$ & $\mathbf{0 . 0 0 2 * *}$ & $\mathbf{0 . 3 5 6}$ \\
$\quad$ Emotion & & & & & & \\
\hline
\end{tabular}

Note: Significant results are set in bold. 
Table 4

Post-hoc Comparisons for the Analysis on Right Insula and Left Amygdala Activation during the Gambling Task.

\begin{tabular}{|c|c|c|c|c|c|}
\hline Interaction & ROIs & Comparisons & $F$ & $p$ & $\eta^{2}$ \\
\hline \multirow[t]{4}{*}{ Cognitive Load $\times$ Emotion } & R_insula & LL: Neu > Neg & 1.94 & 0.177 & 0.078 \\
\hline & & HL: Neg $>$ Neu & 12.69 & $0.002 * *$ & 0.355 \\
\hline & & Neg: $\mathbf{H L}>\mathbf{L L}$ & 5.25 & $0.032 *$ & 0.186 \\
\hline & & Neu: LL > HL & 3.09 & 0.092 & 0.118 \\
\hline \multirow[t]{4}{*}{ Language $\times$ Emotion } & L_amygdala & L1: Neg $>\mathrm{Neu}$ & 3.39 & 0.079 & 0.128 \\
\hline & & L2: Neu $>$ Neg & 4.18 & 0.053 & 0.154 \\
\hline & & Neg: L1 > L2 & 8.71 & $0.007 * *$ & 0.275 \\
\hline & & Neu: L2 > L1 & 0.02 & 0.901 & 0.001 \\
\hline \multirow[t]{16}{*}{ Language $\times$ Cognitive load $\times$ Emotion } & L_amygdala & L1-LL: Neu > Neg & 0.96 & 0.337 & 0.040 \\
\hline & & L1-HL: Neg > Neu & 10.78 & $0.003 * *$ & 0.319 \\
\hline & & L2-LL: Neu > Neg & 1.33 & 0.260 & 0.055 \\
\hline & & L2-HL: Neu > Neg & 4.13 & 0.054 & 0.152 \\
\hline & & L1-Neg: HL > LL & 37.90 & $<0.001 * *$ & 0.622 \\
\hline & & L1-Neu: HL > LL & 0.03 & 0.862 & 0.001 \\
\hline & & L2-Neg: HL > LL & 0.45 & 0.511 & 0.019 \\
\hline & & L2-Neu: HL > LL & 4.29 & $.050 *$ & 0.157 \\
\hline & $\mathrm{R}$ _insula & L1-LL: Neu > Neg & 10.55 & $.004 * *$ & 0.314 \\
\hline & & L1-HL: Neg > Neu & 16.98 & $<.001 * * *$ & 0.425 \\
\hline & & L2-LL: Neg > Neu & 0.25 & .624 & 0.011 \\
\hline & & L2-HL: Neu > Neg & 0.00 & .987 & $<0.001$ \\
\hline & & L1-Neg: HL > LL & 8.66 & $.007 * *$ & 0.274 \\
\hline & & L1-Neu: LL > HL & 10.82 & $.003 * *$ & 0.320 \\
\hline & & L2-Neg: HL > LL & 0.15 & .706 & 0.006 \\
\hline & & L2-Neu: HL > LL & 0.73 & .400 & 0.031 \\
\hline
\end{tabular}

Note: Significant results are set in bold. 


\section{PsychoPhysiological Interaction (PPI) Analysis}

\section{Table 5}

Cognitive Load-dependent Functional Connectivity of the Right Insula ( $p<0.005$, Uncorrected).

\begin{tabular}{|c|c|c|c|c|c|c|}
\hline & & Functional Connectivity Areas & Hemisphere & $\begin{array}{l}\text { Cluster size } \\
\text { (voxels) }\end{array}$ & MNI coordinate $(\mathrm{x}, \mathrm{y}, \mathrm{z})$ & $\mathrm{T}$ value \\
\hline \multirow[t]{2}{*}{ L1 } & R-insula & Dorsal striatum & $\mathrm{R}$ & 8 & 1896 & 4.26 \\
\hline & & Superior Temporal Gyrus & $\mathrm{L}$ & 29 & $-63-4818$ & 4.37 \\
\hline \multirow[t]{3}{*}{$\mathrm{L} 2$} & R-insula & Parahippocampal Gyrus & $\mathrm{R}$ & 26 & $21-24-15$ & 5.80 \\
\hline & & Dorsal striatum & $\mathrm{L}$ & 8 & $-18-6-3$ & 4.30 \\
\hline & & Thalamus_(aal) & $\mathrm{R}$ & 24 & $21-213$ & 6.05 \\
\hline
\end{tabular}




\section{a. Cognitive load-dependent functional connectivity of the right insula} (seed region: $\mathbf{N e g}>$ Neu) in $L 1$ context
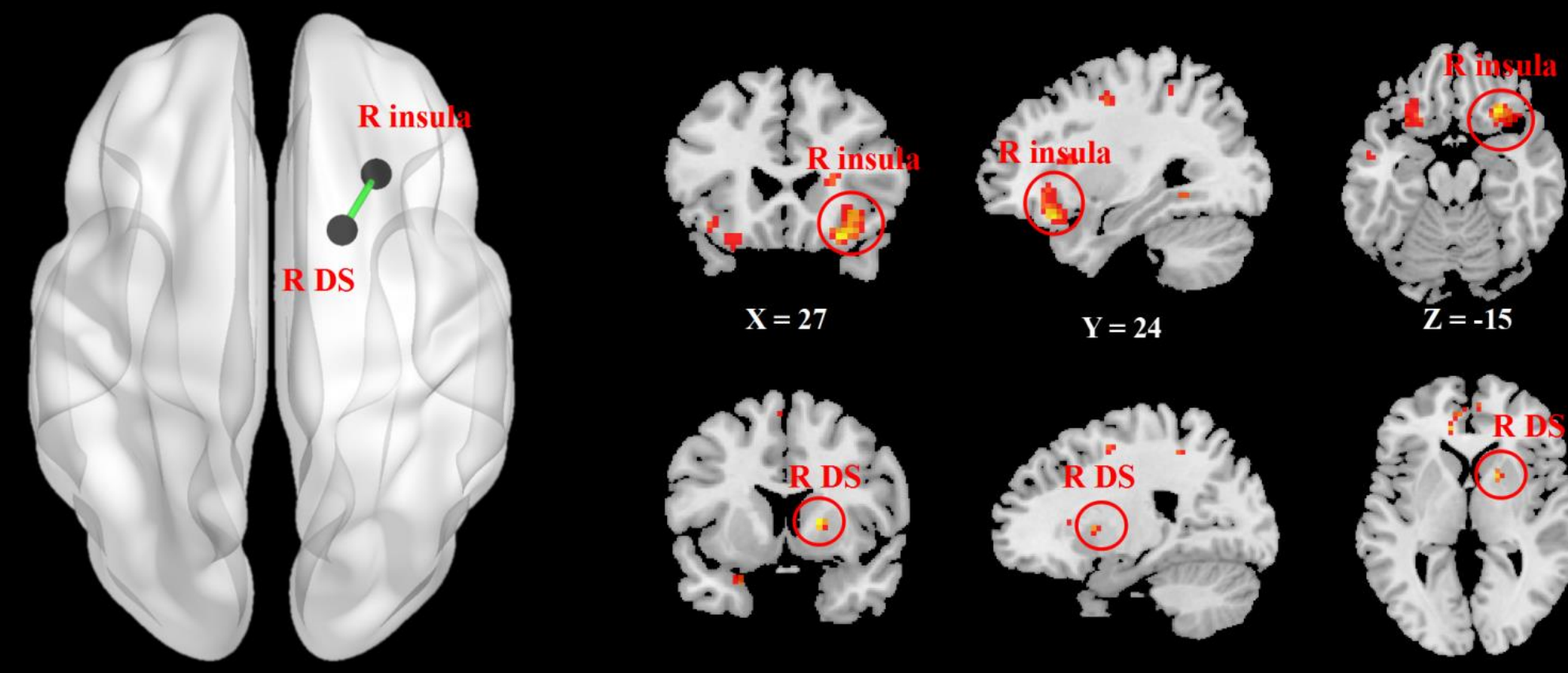

T Value

5
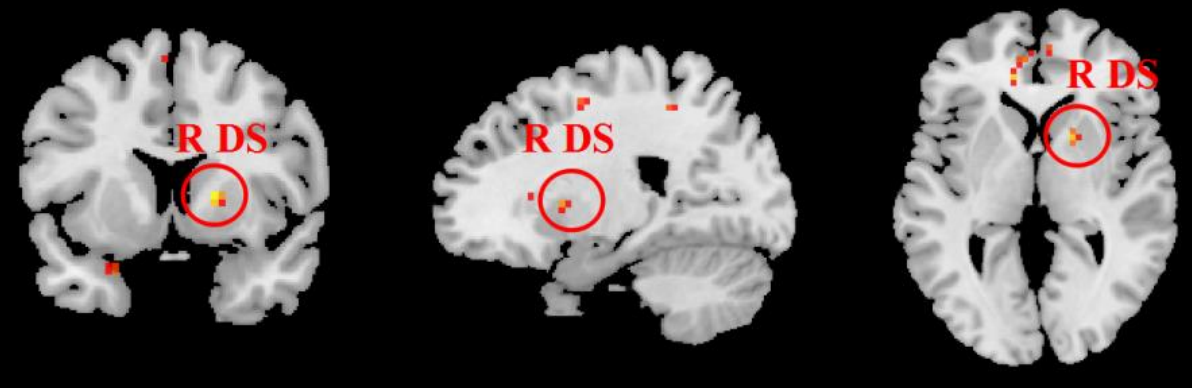

$\mathrm{Z}=6$

b. Cognitive load-dependent functional connectivity of the right insula (seed region: $\mathrm{Neg}>\mathrm{Neu}$ ) in $\mathrm{L} 2$ context
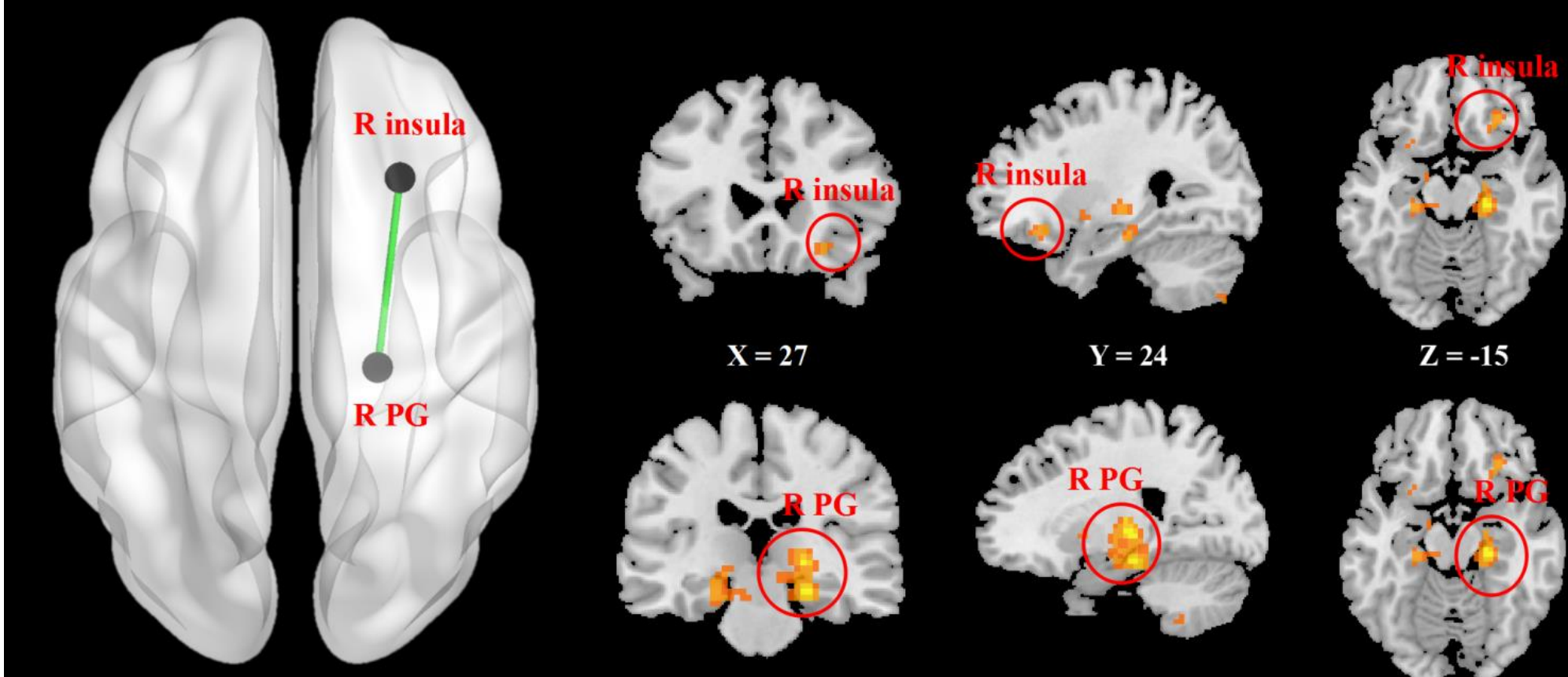

T Value

$\mathbf{X}=\mathbf{2 7}$

$\mathbf{Y}=\mathbf{2 4}$
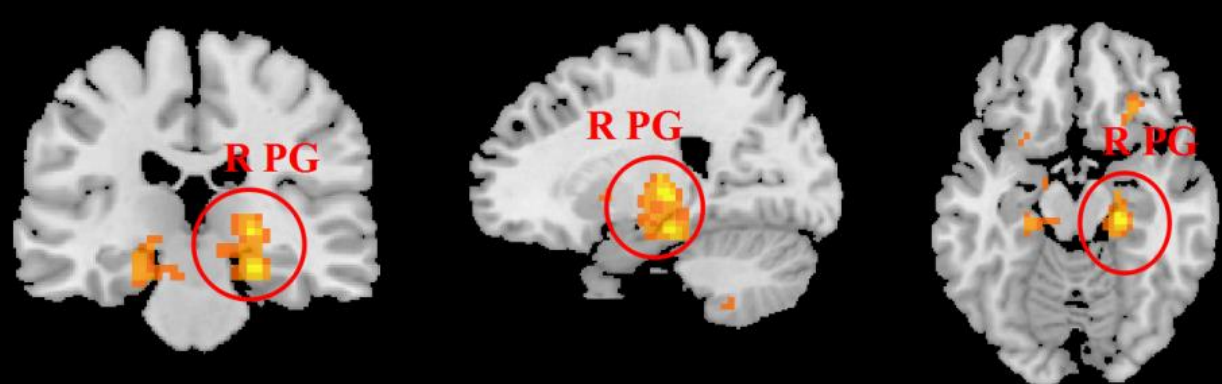

6

(6)

$X=21$

$Y=-24$

$Z=-15$

Figure 5. Cognitive load-dependent functional connectivity of the right insula. Panel (a) displays the coronal, sagittal and axial view for the connectivity between the right insula and the right dorsal striatum (R DS) in L1 context. Panel (b) displays the coronal, sagittal and axial view for the connectivity between the right insula and the right parahippocampal gyrus (R PG) in L2 context. 
Since we found a significant interaction between cognitive load and emotion in the right insula, we selected the difference between right insula activation for negative and neutral words as PPI seeds. In L1 condition, we found a robust activation in regions of the right dorsal striatum (i.e. lentiform nucleus, putamen) dependent on cognitive loading (Appendix E) and a functional interaction between right dorsal striatum (region related to cognitive load) and right insula (region related to emotion) (see Table 5). In addition, there was a significant functional connectivity between the right insula and the left superior temporal gyrus under cognitive loading, but the activation of the left superior temporal gyrus was not itself dependent on the cognitive load condition (-63 48 18). For L2, instead, the right parahippocampal gyrus, responsible for memory processes and here activated differently as a function of cognitive loading (Appendix E), showed a strong connectivity with the right insula. Although the left dorsal striatum and right thalamus also connected with the right insula, they were not part of the cognitive load-dependent functional connectivity.

\section{Correlation Analysis}

Table 6 shows correlations between the activation of left amygdala, right insula, right dorsal striatum or right parahippocampal gyrus and either gambling ratio or participants' risk propensity (assessed with the Risk Attitude Scale), for L1 and L2 condition. A FDR correction $(q=0.05$; Benjamini \& Hochberg, 1995; Benjiamini \& Yekutieli, 2001) was applied to $p$ values which are reported as corrected.

In L1 condition, the activation of left amygdala (L1 High-load negative > L1 Lowload negative) positively correlated with gambling ratio but not with risk propensity 
(see Table 6 and Figure 6a). Participants whose amygdala was activated for negative

L1 words more under cognitive loading than not also gambled more.

In L2 condition, the activation of right insula (L2 High-load negative > L2 Highload neutral) was negatively correlated with gambling ratio but unrelated to risk propensity. Participants whose right insula was activated under cognitive loading more for negative L2 words than for L2 neutral words also gambled less.

\section{Table 6}

Correlations between Gambling Ratio or Risk Propensity and Left Amygdala, Right Insula, Right Dorsal Striatum and Right Parahippocampal Gyrus.

\begin{tabular}{lccccccccc}
\hline & \multicolumn{3}{c}{ Gambling ratio } & \multicolumn{3}{c}{ Risk propensity } \\
\cline { 2 - 10 } & \multicolumn{2}{c}{ L1 } & \multicolumn{2}{c}{ L2 } & \multicolumn{2}{c}{ L1 } & \multicolumn{2}{c}{ L2 } \\
\cline { 2 - 11 } & $r$ & $p$ & $r$ & $p$ & $r$ & $p$ & $r$ & $p$ \\
\cline { 2 - 10 } Left Amygdala & $\mathbf{0 . 6 2}$ & $\mathbf{0 . 0 0 3}$ & 0.24 & 0.331 & -0.13 & 0.786 & 0.20 & 0.300 \\
Right Insula & 0.36 & 0.172 & $\mathbf{- 0 . 4 7}$ & $\mathbf{0 . 0 4 4}$ & -0.11 & 0.722 & -0.06 & 0.939 \\
Right Dorsal Striatum & 0.11 & 0.722 & -0.38 & 0.068 & -0.07 & 0.757 & 0.41 & 0.068 \\
Right Parahippocampal Gyrus & - & - & -0.32 & 0.312 & - & - & 0.10 & 0.673 \\
\hline
\end{tabular}

Note: Significant correlations are set in bold. 


\section{a. The left amgydala activation in L1 Neg HL > L1 Neg LL}
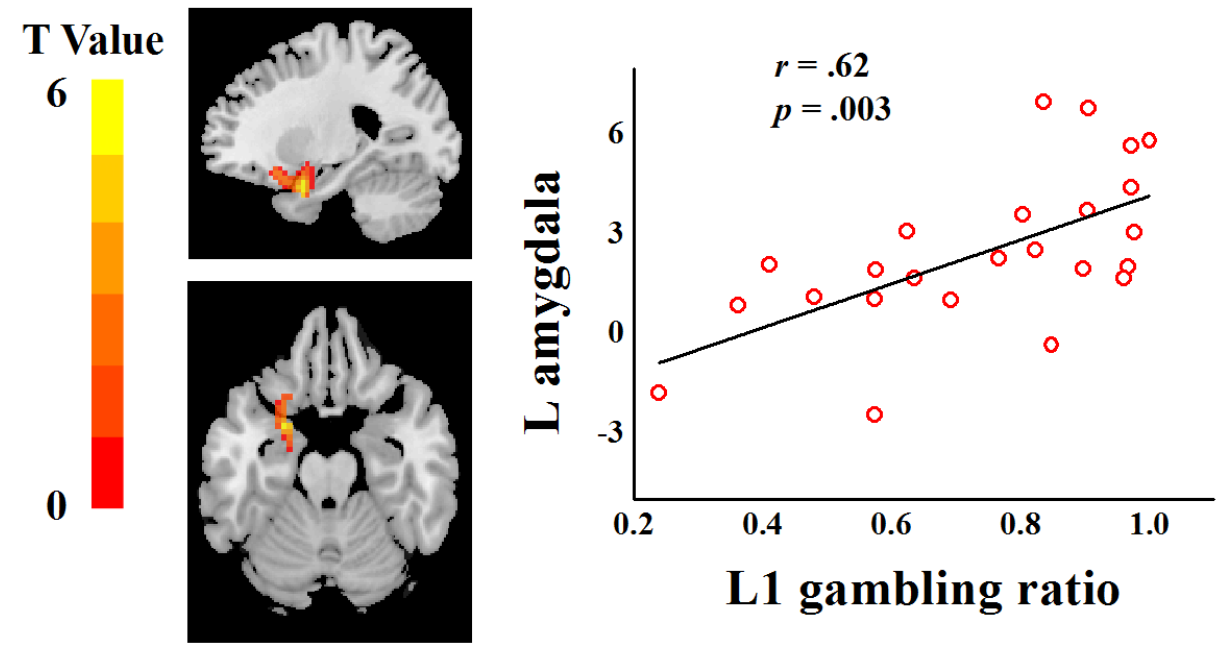

\section{L1 gambling ratio}

\section{b. The right insula in L2 HL Neg > L2 HL Neu}
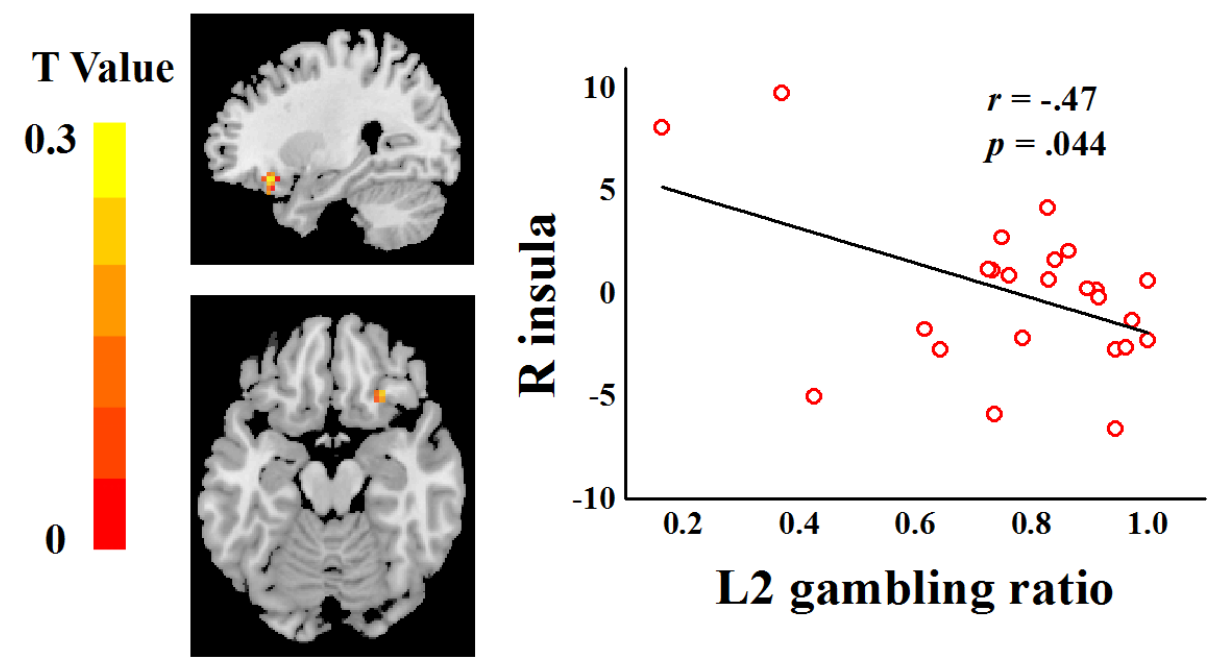

Figure 6. Correlations between gambling ratio and brain activity in left amygdala (a) and right insula (b) regions.

\section{Discussion}

The current study adopted a cross-task design to investigate at the neural level how the interaction between cognition and emotion can be affected by language (L1 vs. L2). We found that activation of the left amygdala and right insula was increased under cognitive loading in L1 negative words condition but not in L2 negative words 
condition. Both left amygdala and right insula modulate emotional processing (Gorka et al., 2019; Hassel et al., 2020; Korgaonkar et al., 2019; Shiv et al., 2005; Xue et al., 2011): the former is known to be involved in sympathetic emotional activation (Eimontaite et al., 2019; Korn \& Bach, 2019; Orem et al., 2019; Williams et al. 2005), and the latter is associated with negative affect and avoidance behavior (Saga et al., 2019; Turel et al., 2020). Here these regions were found to interact differently with cognitive loading depending on the language context.

This study further revealed that cognitive load-dependent connectivity in L1 was different to the one in L2. The increased connectivity with the reward-related striatum in L1 under cognitive loading suggests that cognitive load can enhance emotional sensitivity in L1. By contrast, in L2 context, the connection between the insula and the parahippocampal gyrus, a memory area, indicates that the brain favored the semantics access over the emotion processing.

A different access to emotion in the two languages (native, foreign) may explain the neural-behavioral correlations that we found. While in L1 the gambling ratio was positively correlated with the difference in left amygdala activation between the Highload negative words condition and the Low-load negative words condition, in L2 it was negatively correlated with the difference in right insula activation between the Highload negative words condition and the High-load neutral words condition. This suggests that in L1 cognitive loading can facilitate or deepen the emotional experience leading to a more impulsive decision making, whereas in L2 it can attenuate or hinder the access to emotion leading to more rational decision making. 
The correlation between gambling ratio and left amygdala activation in L1 is in line with research showing that amygdala modulates risk behavior (Takeuchi et al., 2018; van Holstein et al., 2020; Xue et al., 2011). For instance, Zheng et al. (2020) showed that the processing of gambling feedbacks was associated with activation in the bilateral caudate, right posterior insula and amygdala, and that the activation in these areas helps explain foreign language effect in participants' gambling choices. However, while in Zheng et al. (2020) L2 positive words enhanced neural response to rewards, here an enhanced amydgala activation was found in L1 negative words condition. It can be observed that finding that negative words and their associated emotion activation (as reflected by left amygdala activation) lead to impulsive decision making is consistent with work showing that people sometimes make risky decisions when under loss, i.e. while experiencing negative emotions (Scholer et al., 2010).

We also found a correlation between gambling ratio and right insula activation in L2. This area is known to be implicated in top-down control of sympathetic nervous system functioning which is involved in hunger, survival, addiction, negative affect and avoidance behavior (Craig, 2005; Naqvi et al., 2007; Saga et al., 2018; Turel et al., 2020; Xue et al., 2010). Moreover, Arsalidou et al. (2013) reported that the bilateral insula areas were modulated by cognitive loading in a working memory task, strengthening the hypothesis that insula activation reflects both cognitive loading and emotion.

Overall, the correlational results pattern reported here can be explained by different thresholds of lexical-semantic access in the two languages (L1, L2). After processing a L1 word, cognitive resources are often still available to be recruited in the processing 
of the emotional valence of the word. In our study this may have led participants to a more emotional or impulsive decision making. By contrast, cognitive load in L2 hinders or attenuates access to emotion as more cognitive resources are needed to process the lexical-semantic components of the words.

In our cross-task study, participants first completed a Lexical-semantic task trial where they were provided with a L1 or L2 language stimulus, and then made their decision whether to gamble. Thus, the language stimulus can be conceptualized as an anchor. We were interested in assessing under which conditions this anchor would have had an effect on participants' decision making. The anchoring effect is a cognitive heuristic and refers to the process where the individual is systematically biased in their judgment by an information given before the judgment (Beggs \& Graddy, 2009; Furnham \& Boo, 2011; Furnham et al., 2012). For instance, an individual's numerical estimate can be affected by biased estimates toward arbitrary values presented before.

In the native L1 context of our study, bilinguals may have been biased toward a more emotional and less rational decision making by having been anchored to the emotion assessment in the Lexical-semantic task. By contrast, in the foreign L2 context, the achoring effect may have been hindered because cognitive loading and processing did not leave room for emotion processing in the anchoring phase in the first place.

However, it should also be noted that we did not find any significant left amygdala activation specific for negative words vs. neutral words in the Low-load condition in both L1 and L2. A possibility is that the emotion processing of valenced words highly depends on the difficulty of the lexical-semantic processing needed to complete the task 
(Hinojosa et al., 2010; Schacht \& Sommer, 2009b). Perhaps Low-load trials were too simple to process, and participants did not direct their attention to the emotional aspects of the stimuli. By contrast, participants may have been more focused on the emotional aspects in the High-load trials because the higher difficulty of the task increased their attention. Needless to say, this phenomenon closely resembles the germane cognitive loading phenomenon we discussed in the Introduction.

An unexpected result was found in the L1 Low-load condition: the insula, an area associated with emotion detection (Pedale et al., 2019; Simmons et al., 2012; Thom et al., 2012), was activated for the neutral words more than it was for the negative words. A possibility is that emotion detection was processed almost automatically for negative stimuli, but effortfully for neutral stimuli. Under this hypothesis, activation of insula can be seen as reflecting participants' effort in assessing whether neutral words had emotional content or not. Ultimately, however, no emotion can be associated to neutral words, as evidenced by the lack of activation of the amygdala region. Of interest here is that such unexpected effect was not found in L2 context. This further evidence of interaction insensitivity in L2 supports a foreign language effect.

It is worth noting that a number of studies reported that loading cognitive processes reduces emotional influence on judgment and cognition more in general (Berggren et al., 2013; DeFraine, 2016; Mueller et al., 2017; Panasiti et al., 2018; Van Dillena et al., 2009). Instead, at least in L1 context, we found that loading cognitive processes led to increased emotionality: in L1 but not in L2, negative stimuli provoked higher amygdala activity under cognitive loading. Work reporting an emotionality reduction effect often 
uses arithmetic-based tasks to interfere with the processing of affective stimuli (e.g. Chen \& Epps, 2013; Clarke \& Johnstone, 2013; Van Dillen et al., 2009). By contrast, we used linguistic stimuli which already carry an emotional significance. In particular, it can be observed that words can induce different emotional arousal depending on whether they are in L1 or L2. This is so because L1 is learned in a diversified set of situations including negative ones, whereas L2 is acquired and used mainly in decontexted classroom environments where negative experiences are scarce (Atkinson, 2010; Grauwe et al., 2014; Kühne \& Gianelli, 2019). L1 words processing may thus be more closely associated with the emotional brain networks.

These observations help explain why in L1 but not in L2 a germane cognitive load as the one employed in the current study resulted in higher activation of areas associated with emotion processing. This higher emotion activation under cognitive loading in L1 led to a biased decision making where insula showed significant connectivity with the the dorsal striatum, an area related to decision making (Nguyen et al., 2019), action planning (Vink et al., 2005; Zandbelt \& Vink, 2010), motivation (Gemikonakli et al., 2019), reinforcement and reward perception (Pan et al. 2017; Wimmer et al., 2014). Instead, in L2 context, words underwent a more declarative lexico-semantic processing: insula was indeed found to be more connected with the parahippocampal gyrus, which plays an important role in memory encoding and retrieval (Aberg et al., 2020; Bohbot et al., 2015; Murty et al., 2014; Suzuki \& Amaral, 1994). This suggests that cognitive loading in L2 led participants to first make an extra-effort to access the semantics and only later process the emotional valence of the words (Hinojosa et al., 2010). 
In sum, in L1, because of the ease of lexical-semantic access, cognitive loading can be germane and promote access to emotion, eventually affecting decision making. In L2 context, instead, the higher difficulty of the lexical-semantic access combined with cognitive loading can be too taxing for participants' cognitive resources and, as a result, hinder the emotional influence over decision making.

\section{Conclusion}

We investigated the neural substrates underlying the interaction between cognitive load and emotional involvement in bilingual decision making. We found that cognitive loading in L1 but not in L2 facilitated access to emotion which led to a subsequent impulsive decision making. Risky decisions were mediated by the emotion-related regions in both L1 and L2. However, while in L1 cognitive loading promoted emotion as evidenced by increased sensitivity of the dorsal striatum, an area involved in rewardrelated emotion, in L2 it led participants to rely on the parahippocampal gyrus, an area which contributes to the declarative memory formation. Thus, the current findings provide evidence of distinct neural pathways underpinning decision making in native vs. foreign language, opening new avenues for research by highlighting the importance of investigating the complex interaction between cognitive loading and emotional involvement in the context of the foreign language effect. 


\section{References}

Aberg, K. C., Kramer, E. E., \& Schwartz, S. (2020). Interplay between midbrain and dorsal anterior cingulate regions arbitrates lingering reward effects on memory encoding. Nature Communications, 11, 1-14. https://doi.org/10.1038/s41467-020$\underline{15542-\mathrm{Z}}$

Allan, D. (2004). Oxford placement test 2: Test pack. Oxford: Oxford University Press.

Arsalidou, M., Pascual-Leone, J., Johnson, J., Morris, D., \& Taylor, M. J. (2013). A balancing act of the brain: Activations and deactivations driven by cognitive load. Brain and Behavior, 3, 273-285. https://doi.org/10.1002/brb3.128

Atkinson, D. (2010). Extended, embodied cognition and second language acquisition. Applied Linguistics, 31, 599-622.

https://doi.org/10.1093/applin/amq009

Beggs, A., \& Graddy, K. (2009). Anchoring effects: Evidence from art auctions. American Economic Review, 99, 1027-1039. https://doi.org/10.1257/aer.99.3.1027

Berggren, N., Koster, E. H. W., \& Derakshan, N. (2012). The effect of cognitive load in emotional attention and trait anxiety: An eye movement study. Journal of Cognitive Psychology, 24, 79-91. https://doi.org/10.1080/20445911.2011.618450

Berggren, N., Richards, A., Taylor, J., \& Derakshan, N. (2013). Affective attention under cognitive load: reduced emotional biases but emergent anxiety-related costs to inhibitory control. Frontiers in Human Neuroscience, 7, 188. https://doi.org/10.3389/fnhum.2013.00188

Bohbot, V. D., Allen, J. J., Dagher, A., Dumoulin, S. O., Evans, A. C., Petrides, M., ... 
\& Nadel, L. (2015). Role of the parahippocampal cortex in memory for the configuration but not the identity of objects: converging evidence from patients with selective thermal lesions and fMRI. Frontiers in Human Neuroscience, 9, 431. https://doi.org/10.3389/fnhum.2015.00431

Cai, Q., \& Brysbaert, M. (2010). SUBTLEX-CH: Chinese word and character frequencies based on film subtitles. PLoS ONE, 5, e10729. https://doi.org/10.1371/journal.pone.0010729

Caldwell-Harris, C. L. (2015). Emotionality differences between a native and foreign language. Current Directions in Psychological Science, 24, 214-219. https://doi.org/10.1177/0963721414566268

Chen, S., \& Epps, J. (2013). Automatic classification of eye activity for cognitive load measurement with emotion interference. Computer Methods and Programs in Biomedicine, 110, 111-124. https://doi.org/10.1016/j.cmpb.2012.10.021

Costa, A., Foucart, A., Arnon, I., Aparici, M., \& Apesteguia, J. (2014). "Piensa" twice: On the foreign language effect in decision making. Cognition, 130, 236254. https://doi.org/10.1016/j.cognition.2013.11.010

Costa, A., Vives, M. L., \& Corey, J. D. (2017). On language processing shaping decision making. Current Directions in Psychological Science, 26, 146-151. https://doi.org/10.1177/0963721416680263

Craig, A. D. (2009). Emotional moments across time: a possible neural basis for time perception in the anterior insula. Philosophical Transactions of the Royal Society B: Biological Sciences, 364, 1933-1942. https://doi.org/10.1098/rstb.2009.0008 
Debue, N., \& van De Leemput, C. (2014). What does germane load mean? An empirical contribution to the cognitive load theory. Frontiers in Psychology, 5, 1099. https://doi.org/10.3389/fpsyg.2014.01099

DeFraine, W. C. (2016). Differential effects of cognitive load on emotion: Emotion maintenance versus passive experience. Emotion, 16, 459. https://doi.org/10.1037/emo0000140

Dehdar, K., Mahdidoust, S., Salimi, M., Gholami-Mahtaj, L., Nazari, M., Mohammadi, S., ... \& Barkley, V. (2019). Allergen-induced anxiety-like behavior is associated with disruption of medial prefrontal cortex-amygdala circuit. Scientific Reports, 9, 1-13. https://doi.org/10.1038/s41598-019-55539-3

Di, X., Zhang, Z., \& Biswal, B. B. (2019). Understanding psychophysiological interaction and its relations to beta series correlation. bioRxiv, 322073. https://doi.org/10.1101/322073

Díaz-Lago, M., \& Matute, H. (2019). Thinking in a Foreign language reduces the causality bias. Quarterly Journal of Experimental Psychology, 72, 41-51. https://doi.org/10.1177/1747021818755326

Dylman, A. S., \& Bjärtå, A. (2019). When your heart is in your mouth: the effect of second language use on negative emotions. Cognition and Emotion, 33, 1284-1290. https://doi.org/10.1080/02699931.2018.1540403

Eimontaite, I., Schindler, I., De Marco, M., Duzzi, D., Venneri, A., \& Goel, V. (2019). Left amygdala and putamen activation modulate emotion driven decisions in the iterated Prisoner's Dilemma game. Frontiers in Neuroscience, 13, 741. 
https://doi.org/10.3389/fnins.2019.00741

Franconeri, S. L., Alvarez, G. A., \& Cavanagh, P. (2013). Flexible cognitive resources: competitive content maps for attention and memory. Trends in Cognitive Sciences, 17, 134-141. https://doi.org/10.1016/j.tics.2013.01.010

Fujimaki, N., Hayakawa, T., Ihara, A., Wei, Q., Munetsuna, S., Terazono, Y., ... \& Murata, T. (2009). Early neural activation for lexico-semantic access in the left anterior temporal area analyzed by an fMRI-assisted MEG multidipole method. NeuroImage, 44, 1093-1102. https://doi.org/10.1016/j.neuroimage.2008.10.021

Furnham, A. \& Boo, H. C. (2011). A literature review of the anchoring effect. The Journal of Socio-Economics, 40, 35-42.

https://doi.org/10.1016/j.socec.2010.10.008

Furnham, A., Boo, H. C., \& McClelland, A. (2012). Individual differences and the susceptibility to the influence of anchoring cues. Journal of Individual Differences, 33, 89-93. https://doi.org/10.1027/1614-0001/a000076

Gao, S., Zika, O., Rogers, R. D., \& Thierry, G. (2015). Second language feedback abolishes the "hot hand" effect during even-probability gambling. The Journal of Neuroscience, 35, 5983-5989. https://doi.org/10.1523/jneurosci.3622-14.2015

Geipel, J., Hadjichristidis, C., \& Surian, L. (2015). How foreign language shapes moral judgment. Journal of Experimental Social Psychology, 59, 8-17. https://doi.org/10.1016/j.jesp.2015.02.001

Gemikonakli, G., Keay, K. A., Kendig, M. D., Kang, J. W., Corbit, L. H., \& Mor, D. (2019). Altered monoamine levels in the dorsal striatum of the rat are associated 
with alterations in behavioural selection and motivation following peripheral nerve injury and acute stress. European Journal of Neuroscience, 50, 2786-2800. https://doi.org/10.1111/ejn.14518

Gorka, S. M., Young, C. B., Klumpp, H., Kennedy, A. E., Francis, J., Ajilore, O., ... \& Phan, K. L. (2019). Emotion-based brain mechanisms and predictors for SSRI and CBT treatment of anxiety and depression: a randomized trial. Neuropsychopharmacology, 44, 1639-1648. https://doi.org/10.1038/s41386-019$\underline{0407-7}$

Green, D. W. (1998). Mental control of the bilingual lexico-semantic system. Bilingualism: Language and Cognition, 1, 67-81. https://doi.org/10.1017/s1366728998000133

Guex, R., Hofstetter, C., Domínguez-Borràs, J., Méndez-Bértolo, C., Sterpenich, V., Spinelli, L., ... Vuilleumier, P. (2019). Neurophysiological evidence for early modulation of amygdala activity by emotional reappraisal. Biological Psychology, 145, 211-223. https://doi.org/10.1016/j.biopsycho.2019.05.006

Hadjichristidis, C., Geipel, J., and Surian, L. (2018). Breaking magic: Foreign language suppresses superstition. Quarterly Journal of Experimental Psychology 72, 18-28. https://doi.org/10.1080/17470218.2017.1371780

Hasegawa, M., Carpenter, P.A., \& Just, M.A. (2002). An fMRI study of bilingual sentence comprehension and workload. NeuroImage 15, 647-660. https://doi.org/10.1006/nimg.2001.1001

Hassel, S., Sharma, G. B., Alders, G. L., Davis, A. D., Arnott, S. R., Frey, B. N., ... \& 
Müller, D. J. (2020). Reliability of a functional magnetic resonance imaging task of emotional conflict in healthy participants. Human Brain Mapping, 41, 1400-1415. https://doi.org/10.1002/hbm.24883

Hayakawa, S., Costa, A., Foucart, A., \& Keysar, B. (2016). Using a foreign language changes our choices. Trends in Cognitive Sciences, 20, 791-793. https://doi.org/10.1016/j.tics.2016.08.004

Hayakawa, S., Tannenbaum, D., Costa, A., Corey, J. D., \& Keysar, B. (2017). Thinking more or feeling less? Explaining the foreign-language effect on moral judgment. Psychological Science, 28, 1387-1397. https://doi.org/10.1177/0956797617720944

Hinojosa, J. A., Méndez-Bértolo, C., \& Pozo, M. A. (2010). Looking at emotional words is not the same as reading emotional words: Behavioral and neural correlates. Psychophysiology, 47, 748-757. https://doi.org/10.1111/j.1469-8986.2010.00982.x Janak, P. H., \& Tye, K. M. (2015). From circuits to behaviour in the amygdala. Nature, 517, 284-292. https://doi.org/10.1038/nature14188

Keysar, B., Hayakawa, S. L., \& An, S. G. (2012). The foreign-language effect. Psychological Science, 23, 661-668. https://doi.org/10.1177/0956797611432178

Korgaonkar, M. S., Erlinger, M., Breukelaar, I. A., Boyce, P., Hazell, P., Antees, C., ... \& Harris, A. W. (2019). Amygdala activation and connectivity to emotional processing distinguishes asymptomatic patients with bipolar disorders and unipolar depression. Biological Psychiatry: Cognitive Neuroscience and Neuroimaging, 4, 361-370. https://doi.org/10.1016/j.bpsc.2018.08.012

Korn, C. W., \& Bach, D. R. (2019). Minimizing threat via heuristic and optimal policies 
recruits hippocampus and medial prefrontal cortex. Nature Human Behaviour, 3, 733-745. https://doi.org/10.1038/s41562-019-0603-9

Korn, C. W., Heekeren, H. R., \& Oganian, Y. (2019). The framing effect in a monetary gambling task is robust in minimally verbal language switching contexts. Quarterly Journal of Experimental Psychology, 72, 52-59.

https://doi.org/10.1177/1747021818769259

Korucuoglu, O., Harms, M. P., Kennedy, J. T., Golosheykin, S., Astafiev, S. V., Barch, D. M., \& Anokhin, A. P. (2020). Adolescent decision-making under risk: neural correlates and sex differences. Cerebral Cortex, 30, 2691-2707. https://doi.org/10.1093/cercor/bhz269

Kühne, K., \& Gianelli, C. (2019). Is embodied cognition bilingual? Current evidence and perspectives of the embodied cognition approach to bilingual language processing. Frontiers in Psychology, 10, 108.

https://doi.org/10.3389/fpsyg.2019.00108

Liang, L., \& Chen, B. (2014). Processing morphologically complex words in secondlanguage learners: The effect of proficiency. Acta Psychologica, 150, 69-79. https://doi.org/10.1016/j.actpsy.2014.04.009

Lieder, F., \& Griffiths, T. L. (2020). Resource-rational analysis: understanding human cognition as the optimal use of limited computational resources. Behavioral and Brain Sciences, 43, 1-85. https://doi.org/10.1017/s0140525x1900061x

Liu, H., Liang, L., Dunlap, S., Fan, N., \& Chen, B. (2016). The effect of domain-general inhibition-related training on language switching: An ERP study. Cognition, 146, 
264-276. https://doi.org/10.1016/j.cognition.2015.10.004

McLaren, D. G., Ries, M. L., Xu, G., \& Johnson, S. C. (2012). A generalized form of context-dependent psychophysiological interactions (gPPI): a comparison to standard approaches. NeuroImage, 61, 1277-1286.

https://doi.org/10.1016/j.neuroimage.2012.03.068

Méndez-Bértolo, C., Moratti, S., Toledano, R., Lopez-Sosa, F., Martínez-Alvarez, R., Mah, Y. H., ... \& Strange, B. A. (2016). A fast pathway for fear in human amygdala. Nature Neuroscience, 19, 1041-1049. https://doi.org/10.1038/nn.4324

Montero-Melis, G., Isaksson, P., Van Paridon, J., \& Ostarek, M. (2020). Does using a foreign language reduce mental imagery? Cognition,196, 104134. https://doi.org/10.1016/j.cognition.2019.104134

Mueller, S. C., Cromheeke, S., Siugzdaite, R., \& Boehler, C. N. (2017). Evidence for the triadic model of adolescent brain development: Cognitive load and taskrelevance of emotion differentially affect adolescents and adults. Developmental Cognitive Neuroscience, 26, 91-100. https://doi.org/10.1016/j.dcn.2017.06.004

Murty, V. P., \& Adcock, R. A. (2014). Enriched encoding: reward motivation organizes cortical networks for hippocampal detection of unexpected events. Cerebral Cortex, 24, 2160-2168. https://doi.org/10.1093/cercor/bht063

Nakamura, K., Inomata, T., \& Uno, A. (2020). Left amygdala regulates the cerebral reading network during fast emotion word processing. Frontiers in Psychology, 11, 1. https://doi.org/10.3389/fpsyg.2020.00001

Namburi, P., Beyeler, A., Yorozu, S., Calhoon, G. G., Halbert, S. A., Wichmann, R., ... 
\& Wickersham, I. R. (2015). A circuit mechanism for differentiating positive and negative associations. Nature, 520, 675-678. https://doi.org/10.1038/nature14366

Naqvi, N. H., Rudrauf, D., Damasio, H., \& Bechara, A. (2007). Damage to the insula disrupts addiction to cigarette smoking. Science, 315, 531-534. https://doi.org/10.1227/01.neu.0000309481.58232.a8

Nguyen, D., Alushaj, E., Erb, S., \& Ito, R. (2019). Dissociative effects of dorsomedial striatum D1 and D2 receptor antagonism in the regulation of anxiety and learned approach-avoidance conflict decision-making. Neuropharmacology, 146, 222-230. https://doi.org/10.1016/j.neuropharm.2018.11.040

Oganian, Y., Korn, C. W., \& Heekeren, H. R. (2016). Language switching - but not foreign language use per se - reduces the framing effect. Journal of Experimental Psychology: Learning, Memory, and Cognition, 42, 140-148. https://doi.org/10.1037/xlm0000161

Orem, T. R., Wheelock, M. D., Goodman, A. M., Harnett, N. G., Wood, K. H., Gossett, E. W., ... \& Knight, D. C. (2019). Amygdala and prefrontal cortex activity varies with individual differences in the emotional response to psychosocial stress. Behavioral Neuroscience, 133, 203-211. https://doi.org/10.1037/bne0000305

Paas, F., \& Sweller, J. (2014). Implications of cognitive load theory for multimedia learning. The Cambridge Handbook of Multimedia Learning, 27, 27-42. https://doi.org/10.1017/cbo9781139547369.004

Pan, P. M., Sato, J. R., Salum, G. A., Rohde, L. A., Gadelha, A., Zugman, A., ... \& Pine, D. S. (2017). Ventral striatum functional connectivity as a predictor of adolescent 
depressive disorder in a longitudinal community-based sample. American Journal of Psychiatry, 174, 1112-1119. https://doi.org/10.1176/appi.ajp.2017.17040430

Panasiti, M. S., Ponsi, G., Monachesi, B., Lorenzini, L., Panasiti, V., \& Aglioti, S. M. (2019). Cognitive load and emotional processing in psoriasis: a thermal imaging study. Experimental Brain Research, 237, 211-222.

https://doi.org/10.1007/s00221-018-5416-y

Pauligk, S., Kotz, S. A., \& Kanske, P. (2019). Differential impact of emotion on semantic processing of abstract and concrete words: ERP and fMRI evidence. Scientific Reports, 9, 1-13. https://doi.org/10.1038/s41598-019-50755-3

Pavlenko, A. (2012). Affective processing in bilingual speakers: Disembodied cognition? International Journal of Psychology, 47, 405-428. https://doi.org/10.1080/00207594.2012.743665

Pedale, T., Macaluso, E., \& Santangelo, V. (2019). Enhanced insular/prefrontal connectivity when resisting from emotional distraction during visual search. Brain Structure and Function, 224, 2009-2026. https://doi.org/10.1007/s00429-019$\underline{01873-1}$

Phan, K. L., Wager, T. D., Taylor, S. F., \& Liberzon, I. (2004). Functional neuroimaging studies of human emotions. CNS Spectrums, 9, 258-266. https://doi.org/10.1017/s1092852900009196

Ponari, M., Rodríguez-Cuadrado, S., Vinson, D., Fox, N., Costa, A., \& Vigliocco, G. (2015). Processing advantage for emotional words in bilingual speakers. Emotion, 15, 644. https://doi.org/10.1037/emo0000061 
Pu, J., Peng, D., Demaree, H. A., Song, Y., Wei, J., \& Xu, L. (2005). The recognition potential: Semantic processing or the detection of differences between stimuli? Cognitive Brain Research, 25, 273-282. https://doi.org/10.1016/j.cogbrainres.2005.06.001

Runnqvist, E., Strijkers, K., \& Costa, A. (2019). Error-based learning and lexical competition in word production: Evidence from multilingual naming. PLoS ONE, 14, e0213765. https://doi.org/10.1371/journal.pone.0213765

Saga, Y., Ruff, C. C., \& Tremblay, L. (2019). Disturbance of approach-avoidance behaviors in non-human primates by stimulation of the limbic territories of basal ganglia and anterior insula. European Journal of Neuroscience, 49, 687-700. https://doi.org/10.1111/ejn.14201

Schacht, A., \& Sommer, W. (2009). Emotions in word and face processing: early and late cortical responses. Brain and Cognition, 69, 538-550. https://doi.org/10.1016/j.bandc.2008.11.005

Schneider, S., Beege, M., Nebel, S., \& Rey, G. D. (2018). A meta-analysis of how signaling affects learning with media. Educational Research Review, 23, 1-24. https://doi.org/10.1016/j.edurev.2017.11.001

Scholer, A. A., Zou, X., Fujita, K., Stroessner, S. J., \& Higgins, E. T. (2010). When risk seeking becomes a motivational necessity. Journal of Personality and Social Psychology, 99, 215-231. https://doi:10.1037/2333-8113.1.s.91

Sharpe, M. J., Stalnaker, T., Schuck, N. W., Killcross, S., Schoenbaum, G., \& Niv, Y. (2019). An integrated model of action selection: distinct modes of cortical control 
of striatal decision making. Annual Review of Psychology, 70, 53-76.

https://doi.org/10.1146/annurev-psych-010418-102824

Sheikh, N. A., \& Titone, D. (2016). The embodiment of emotional words in a second language: An eye-movement study. Cognition and Emotion, 30, 488-500. https://doi.org/10.1080/02699931.2015.1018144

Shiv, B., Loewenstein, G., Bechara, A., Damasio, H., \& Damasio, A. R. (2005). Investment behavior and the negative side of emotion. Psychological Science, 16, 435-439. https://doi.org/10.1111/j.0956-7976.2005.01553.x

Simmons, W. K., Avery, J. A., Barcalow, J. C., Bodurka, J., Drevets, W. C., \& Bellgowan, P. (2012). Keeping the body in mind: Insula functional organization and functional connectivity integrate interoceptive, exteroceptive, and emotional awareness. Human Brain Mapping, 34, 2944-2958.

https://doi.org/10.1002/hbm.22113

Stephan, K. E., Marshall, J. C., Friston, K. J., Rowe, J. B., Ritzl, A., Zilles, K., \& Fink, G. R. (2003). Lateralized cognitive processes and lateralized task control in the human brain. Science, 301, 384-386. https://doi.org/10.1126/science.1086025

Stiller, K. D., \& Schworm, S. (2019). Game-based learning of the structure and functioning of body cells in a foreign language: effects on motivation, cognitive load, and performance. Frontiers in Education, 4, 18.

https://doi.org/10.3389/feduc.2019.00018

Sulpizio, S., Toti, M., Del Maschio, N., Costa, A., Fedeli, D., Job, R., \& Abutalebi, J. (2019). Are you really cursing? Neural processing of taboo words in native and 
foreign language. Brain and Language, 194, 84-92.

https://doi.org/10.1016/j.bandl.2019.05.003

Suzuki, W. L., \& Amaral, D. G. (1994). Perirhinal and parahippocampal cortices of the macaque monkey: cortical afferents. Journal of Comparative Neurology, 350, 497533. https://doi.org/10.1002/cne.903500402

Takeuchi, H., Tsurumi, K., Murao, T., Mizuta, H., Murai, T., \& Takahashi, H. (2019). Amygdala volume is associated with risky probability cognition in gambling disorder. Addiction Biology, 24, 802-810. https://doi.org/10.1111/adb.12640

Thom, N. J., Johnson, D. C., Flagan, T., Simmons, A. N., Kotturi, S. A., Van Orden, K. F., ... Paulus, M. P. (2012). Detecting emotion in others: increased insula and decreased medial prefrontal cortex activation during emotion processing in elite adventure racers. Social Cognitive and Affective Neuroscience, 9, 225-231. https://doi.org/10.1093/scan/nss127

Turel, O., He, Q., Wei, L., \& Bechara, A. (2020). The role of the insula in internet gaming disorder. Addiction Biology, e12894. https://doi.org/10.1111/adb.12894

Tye, K. M., Prakash, R., Kim, S. Y., Fenno, L. E., Grosenick, L., Zarabi, H., ... \& Deisseroth, K. (2011). Amygdala circuitry mediating reversible and bidirectional control of anxiety. Nature, 471, 358-362. https://doi.org/10.1038/nature09820

Van Dillen, L. F., Heslenfeld, D. J., \& Koole, S. L. (2009). Tuning down the emotional brain: an fMRI study of the effects of cognitive load on the processing of affective images. NeuroImage, 45, 1212-1219.

https://doi.org/10.1016/j.neuroimage.2009.01.016 
van Holstein, M., MacLeod, P. E., \& Floresco, S. B. (2020). Basolateral amygdala nucleus accumbens circuitry regulates optimal cue-guided risk/reward decision making. Progress in Neuro-Psychopharmacology and Biological Psychiatry, 98, 109830. https://doi.org/10.1016/j.pnpbp.2019.109830

Vink, M., Kahn, R. S., Raemaekers, M., van den Heuvel, M., Boersma, M., \& Ramsey, N. F. (2005). Function of striatum beyond inhibition and execution of motor responses. Human Brain Mapping, 25, 336-344.

https://doi.org/10.1002/hbm.20111

Vroomen, J., Driver, J., \& De Gelder, B. (2001). Is cross-modal integration of emotional expressions independent of attentional resources? Cognitive, Affective, \& Behavioral Neuroscience, 1, 382-387. https://doi.org/10.3758/cabn.1.4.382

Wang, Y., Liming, Z., \& Yuejia, L. (2008). Preliminary compilation and evaluation of Chinese Emotional Words System. Chinese Journal of Mental Health, 22, 608-612.

Weber, E. U., Blais, A. R., \& Betz, N. E. (2002). A domain-specific risk-attitude scale: Measuring risk perceptions and risk behaviors. Journal of Behavioral Decision Making, 15, 263-290. https://doi.org/10.1002/bdm.414

Williams, L. M., Barton, M. J., Kemp, A. H., Liddell, B. J., Peduto, A., Gordon, E., \& Bryant, R. A. (2005). Distinct amygdala-autonomic arousal profiles in response to fear signals in healthy males and females. NeuroImage, 28, 618-626. https://doi.org/10.1016/j.neuroimage.2005.06.035

Wimmer, G. E., Braun, E. K., Daw, N. D., \& Shohamy, D. (2014). Episodic memory encoding interferes with reward learning and decreases striatal prediction errors. 
The Journal of Neuroscience, 34, 14901-14912.

https://doi.org/10.1523/jneurosci.0204-14.2014

Xue, G., Lu, Z., Levin, I. P., \& Bechara, A. (2010). The impact of prior risk experiences on subsequent risky decision-making: the role of the insula. NeuroImage, 50, 709716. https://doi.org/10.1016/j.neuroimage.2009.12.097

Yan, C. G., Wang, X. D., Zuo, X. N., \& Zang, Y. F. (2016). DPABI: data processing \& analysis for (resting-state) brain imaging. Neuroinformatics, 14, 339-351. https://doi.org/10.1007/s12021-016-9299-4

Zandbelt, B. B., \& Vink, M. (2010). On the role of the striatum in response inhibition. PLoS ONE, 5, e13848. https://doi.org/10.1371/journal.pone.0013848

Zeng, J., Liu, M., Hou, X., Zhang, Q., Chen, H., \& Su, L. (2020). Can genes modulate anchoring effect? International Journal of Psychology. https://doi.org/10.1002/ijop.12669

Zhang, Y., Zhou, W., Wang, S., Zhou, Q., Wang, H., Zhang, B., ... \& Wang, X. (2019). The roles of subdivisions of human insula in emotion perception and auditory processing. Cerebral Cortex, 29, 517-528. https://doi.org/10.1093/cercor/bhx334

Zheng, L., Mobbs, D., \& Yu, R. (2020). The behavioral and neural basis of foreign language effect on risk-taking. Neuropsychologia, 136, 107290. https://doi.org/10.1016/j.neuropsychologia.2019.107290 


\section{Appendix A. Oxford Placement Test}

Instruction 1: Please tick the corresponding number you think is the correct answer.

\begin{tabular}{|c|c|}
\hline 1 & Water $\quad$ at a temperature of $0^{\circ} \mathrm{C}$. \\
\hline & 1、 be freezing; 2、 freezes; 3 、 is freezing. \\
\hline \multirow[t]{2}{*}{2} & In some countries ___ dark all the time in winter. \\
\hline & 1、 there is; 2、 is; 3 , it is \\
\hline \multirow[t]{2}{*}{3} & In some countries people wear light clothes \\
\hline & 1、 for keeping; 2、 to keep; 3、 for to keep. \\
\hline \multirow[t]{2}{*}{4} & In Madeira they have ____ weather almost all year. \\
\hline & 1、 the good; 2、 good; 3、 a good. \\
\hline \multirow[t]{2}{*}{5} & Most Mediterranean countries are___ in October than in April. \\
\hline & 1、 more warm; 2、 the more warm; 3、 warmer. \\
\hline \multirow[t]{2}{*}{6} & Parts of Australia don't have ___ rain for long periods. \\
\hline & 1、 the; 2、 some; C、 any. \\
\hline \multirow[t]{2}{*}{7} & In the Arctic and Antarctic ___ a lot of snow. \\
\hline & 1、 it is; 2、 there is; 3 , it has. \\
\hline \multirow[t]{2}{*}{8} & Climate is very important in ___ people's lives. \\
\hline & 1、 most ; 2、 of most ; 3、 the most. \\
\hline \multirow[t]{2}{*}{9} & Even now there is ___ we can do to control the weather. \\
\hline & 1、 little; 2、 few; 3、 less. \\
\hline \multirow[t]{2}{*}{10} & In the future ___ to get a lot of power from the sun. \\
\hline & 1、 We'll need; 2、 We are needing; 3、 We can need. \\
\hline \multirow[t]{2}{*}{11} & Pele is still ___ famous footballer in the world. \\
\hline & 1、 the most; 2、 most; 3 、 the more. \\
\hline \multirow[t]{2}{*}{12} & He __ born in 1940. \\
\hline & 1、 had been; 2、 is; 3、 was. \\
\hline \multirow[t]{2}{*}{13} & His mother __ him to be a footballer. \\
\hline & 1、 not want; 2、 wasn't wanting; 3、 didn't want. \\
\hline 14 & But he ___ to watch his father play. \\
\hline
\end{tabular}


1、 used; 2、 ought; 3、 has used.

15 His father __ practice everyday.

1、 made him to; 2、 made him ; 3、 would make him to.

16 He learned to use ___ and his right.

1、 or his left foot or ; 2、 and his left foot and; 3、 both his left foot.

17 He got the name Pele when he

1、 had only ten years; 2、 was only ten; 3、 was only ten years.

18 By 1956 he ___ Santos and had scored in his first game.

1、 joined ; 2、 had joined; 3、 has joined.

19 In 1957 he __ for the Brazilian national team.

1、 has been picked; 2、was picked ; 3、 was picking.

20 The World Cup Finals were in 1958 and Pele was looking forward to

1、 playing; 2、 to play; 3、 to be playing.

21 But he hurt __ knee in a game in Brazil.

1、 the; 2、 his; 3、 this.

22 He thought he be able to play in the finals in Sweden.

1、 isn't going to; 2、 couldn't ; 3、 wasn't going to.

23 If he ___ so important to the team, he would have been left behind.

1、 hadn't been; 2、weren't; 3、 wouldn't be.

24 But he was __ brilliant player, they took him anyway.

1、 a such; 2、 such a; 3、 a so.

25 And he was injured, he helped Brazil to win the final.

1、 even though ; 2、 even so; 3、 in spite of. 
Instruction 2: Please tick the corresponding number you think is the correct answer in the table after the passage.

The history of the World Cup is 26 one. Football 27 played for 28 a hundred years, but the first World Cup competition _ـ29 held until 1930. Uruguay 30 the Olympic football final in 1924 and 1928 and wanted _ 31 World Champions for the third time. Four teams entered from Europe, but with _ $\underline{32}$ _ success. It was the first time __ $\underline{33}$ _ professional teams _ 34 for a world title. It wasn't until four years___ 35 _ that a European team succeeded _ 36 _ for $\_\underline{37}$ first time. The 1934 World Cup was again won by_ $\underline{38}$ __ home team, __ 39 has been the case several times since then. The 1934 final was __ $\underline{40}$ two European teams, Czechoslovakia and Italy, _ 41 won, went on 42 the 1938 final. Winning successive finals is something that ___ 43 achieved again until Brazil did $\_44 \quad$ in 1958 and 1962. If Brazil__ $45 \quad$ in 1966, then the Authorities would have needed to _ـ $\underline{46}$ the original World Cup replaced. But England stopped the Brazilians __ 47 a successive win. An England player, Geoff Hurst, scored three goals in the final and won it almost _ـ 48 _ 1966 proved 49 the last year that England _ _ 50 _ even qualify for the finals till 1982, though they got in as winners in 1970 . 


\begin{tabular}{|c|c|}
\hline 26 & 2、 a quite \\
\hline 27 & 1、 has been \\
\hline 28 & 3、 more that \\
\hline 29 & 3、 was not being \\
\hline 30 & 2、 were winning \\
\hline 31 & 2、 being \\
\hline 32 & 1、 a little \\
\hline 33 & 2、 that 3、 when \\
\hline 34 & 2、 would play \\
\hline 35 & 2、 more 3、 further \\
\hline 36 & 2、 in winning \\
\hline 37 & 1、 the 2、a \\
\hline 38 & 1、 a 2、 the \\
\hline 39 & 2、 this 3、 which \\
\hline 40 & 2、 between 3、 against \\
\hline 41 & 1、 which \\
\hline 42 & 2、 winning 3、 to have won \\
\hline 43 & 3、 has not been \\
\hline 44 & 2、 these \\
\hline 45 & 1、 would have won 2、 would win \\
\hline 46 & 3、 make \\
\hline 47 & 2、 getting \\
\hline 48 & 1、 by his own 2、 on himself. \\
\hline 49 & 2、 as being 3、 to be \\
\hline 50 & 2、 will 3、 did \\
\hline
\end{tabular}




\section{Appendix B. Domain-specific Risk-attitude Scale}

For each of the following statements, please indicate the likelihood of engaging in each activity. Provide a rating from 1 to 5 , using the following scale:

\begin{tabular}{|l|l|l|}
\hline \multicolumn{2}{|c|}{$\begin{array}{l}1 \\
\text { Extremely unlikely }\end{array}$} \\
\hline A1 & $\begin{array}{l}\text { Betting a day's income on the outcome of a sporting event (e.g. } \\
\text { baseball, soccer, or football). }\end{array}$ & \\
\hline A2 & Gambling a week's income at a casino. & \\
\hline A3 & Betting a day's income at the horse races. & \\
\hline A4 & Betting a day's income at a high stake poker game. & \\
\hline B5 & Regularly riding your bicycle without a helmet. & \\
\hline B6 & Eating 'expired' food products that still 'look okay'. & \\
\hline B7 & Never wearing a seatbelt. & \\
\hline B8 & Not wearing a helmet when riding a motorcycle. & \\
\hline B9 & Engaging in unprotected sex. & \\
\hline C10 & Wearing provocative or unconventional clothes on occasion. & \\
\hline C11 & $\begin{array}{l}\text { Deciding to share an apartment with someone you don't know } \\
\text { well. }\end{array}$ & \\
\hline C12 & Raise your hand to answer the teacher's questions in class & \\
\hline C13 & $\begin{array}{l}\text { Arguing with a friend who has a very different opinion on an } \\
\text { issue. }\end{array}$ & \\
\hline C14 & After dating someone you like, ask how he feels & \\
\hline C15 & $\begin{array}{l}\text { Speaking your mind about an unpopular issue at a social } \\
\text { occasion. }\end{array}$ & $\begin{array}{l}\text { Periodically engaging in a dangerous sport (e.g. mountain } \\
\text { climbing or sky diving). }\end{array}$ \\
\hline D16 & \\
\hline D17 & Walking home alone at night in a somewhat unsafe area of town. & \\
\hline D18 & Chasing a tornado or hurricane by car to take dramatic photos. & \\
\hline D19 & Going whitewater rafting during rapid water flows in the spring. & \\
\hline
\end{tabular}




\section{Appendix C. Word List}

The first eight elements were practice items, the remaining were experimental items.

\begin{tabular}{|c|c|c|c|}
\hline \multicolumn{2}{|c|}{ Chinese } & \multicolumn{2}{|l|}{ English } \\
\hline \multicolumn{4}{|c|}{ Warm-up words } \\
\hline \multicolumn{2}{|l|}{ 马路 } & \multicolumn{2}{|l|}{ floor } \\
\hline \multicolumn{2}{|l|}{ 食物 } & work & \\
\hline \multicolumn{4}{|c|}{ Warm-up pseudo-words } \\
\hline \multirow[t]{2}{*}{ 工昨 } & & & WETER \\
\hline & 時涧 & & COD \\
\hline \multicolumn{4}{|c|}{ Formal words } \\
\hline 声音 & 聲音 & sound & SOUND \\
\hline 石头 & 石頭 & stone & STONE \\
\hline 学生 & 學生 & student & STUDENT \\
\hline 白纸 & 白紙 & paper & PAPER \\
\hline 数字 & 數字 & number & NUMBER \\
\hline 电话 & 電話 & phone & PHONE \\
\hline 盘子 & 盤子 & plate & PLATE \\
\hline 灯光 & 燈光 & light & LIGHT \\
\hline 苹果 & 蘋果 & apple & APPLE \\
\hline 手表 & 手錶 & watches & WATCHES \\
\hline 山脉 & 山脈 & mountain & MOUNTAIN \\
\hline 说话 & 說話 & speak & SPEAK \\
\hline 新闻 & 新聞 & news & NEWS \\
\hline 产品 & 產品 & product & PRODUCT \\
\hline 枕头 & 枕頭 & pillow & PILLOW \\
\hline 报告 & 報告 & keyboard & KEYBOARD \\
\hline 键盘 & 鍵盤 & report & REPORT \\
\hline 书桌 & 書桌 & table & TABLE \\
\hline 系统 & 系統 & system & SYSTEM \\
\hline 铅笔 & 鉛筆 & pencil & PENCIL \\
\hline 该死 & 輕視 & damn & DAMN \\
\hline 反感 & 怴悔 & hate & HATE \\
\hline 糟糕 & 悲觀 & terrible & TERRIBLE \\
\hline 抱慊 & 諷刺 & sorry & SORRY \\
\hline 耻辱 & 恥辱 & shame & SHAME \\
\hline 厌恶 & 厭惡 & sick & SICK \\
\hline 恶心 & 啞心 & disgust & DISGUST \\
\hline 贪婪 & 貪婪 & greedy & GREEDY \\
\hline 恐惧 & 恐懼 & fear & FEAR \\
\hline 尴尬 & 尷䛈 & awkward & AWKWARD \\
\hline
\end{tabular}




\begin{tabular}{|c|c|c|c|}
\hline 责备 & 責備 & scold & SCOLD \\
\hline 沮丧 & 沮喪 & depressed & DEPRESSED \\
\hline 担忧 & 擔憂 & worried & WORRIED \\
\hline 疯狂 & 瘋狂 & crazy & CRAZY \\
\hline 悲伤 & 悲傷 & fear & FEAR \\
\hline 肮脏 & 骬髒 & dirty & DIRTY \\
\hline 焦虑 & 焦慮 & anxiety & ANXIETY \\
\hline 残酷 & 殘酷 & cruel & CRUEL \\
\hline 质疑 & 質疑 & suspect & SUSPECT \\
\hline 消极 & 消極 & Negative & Negative \\
\hline \multicolumn{4}{|c|}{ Formal pseudo-word } \\
\hline 菇儿 & 菇兒 & patilnt & PATILNT \\
\hline 打驾 & 打駕 & orphen & ORPHEN \\
\hline 纱漠 & 紗漠 & flyy & FLYY \\
\hline 呕仕 & 嘔仕 & hynger & HYNGER \\
\hline 病认 & 病認 & faght & FAGHT \\
\hline 苍绳 & 蒼繩 & disaple & DISAPLE \\
\hline 掺疾 & 摻疾 & debert & DEBERT \\
\hline 失呗 & 失唄 & taers & TAERS \\
\hline 眼钼 & 眼鉬 & failura & FAILURA \\
\hline 饥娥 & 饑娥 & vommt & VOMMT \\
\hline
\end{tabular}


Appendix D. Model Parameters for the Best-fitting Generalized Linear Mixed Model in Lexico-semantic Task and Gambling Task

\section{Table D1}

Model Parameters for the Best-fitting Generalized Linear Mixed Model on Accuracy in the Lexico-semantic Task.

$\beta \quad S E \frac{\text { Contrast }}{2}$

\begin{tabular}{lcccc}
\hline Fixed effects & 3.76 & 0.29 & 12.78 & $<0.001^{* * *}$ \\
Intercept & -1.55 & 0.29 & -5.40 & $<0.001^{* * *}$ \\
Language & -2.89 & 0.27 & -10.60 & $<0.001^{* * *}$ \\
Cognitive load & 0.59 & 0.42 & 1.40 & 0.468 \\
Emotion & 2.49 & 0.33 & 7.67 & $<0.001^{* * *}$ \\
Language $\times$ Cognitive load & 0.41 & 0.48 & 0.85 & 0.849 \\
Language $\times$ Emotion & -0.06 & 0.44 & -0.13 & 1.000 \\
Cognitive load $\times$ Emotion & 0.10 & 0.55 & 0.19 & 1.000 \\
Language $\times$ Cognitive load $\times$ Emotion & & & & \\
Random effects & 0.58 & 0.76 & & \\
Participants & & & & \\
\hline
\end{tabular}




\section{Table D2}

Model Parameters for the Best-fitting Linear Mixed Model on Reaction Times in the Lexico-semantic Task.

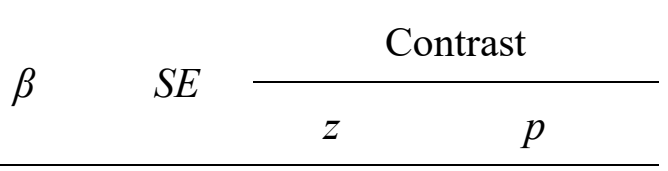

Fixed effects

\begin{tabular}{lcccc} 
Intercept & 688.06 & 30.70 & 22.41 & $<0.001^{* * *}$ \\
Language & 126.45 & 33.09 & 3.82 & $0.001^{* *}$ \\
Cognitive load & 236.10 & 33.88 & 6.97 & $<0.001^{* * *}$ \\
Emotion & -43.59 & 32.82 & -1.33 & 0.619 \\
Language $\times$ Cognitive load & -16.51 & 47.62 & -0.35 & 0.999 \\
Language $\times$ Emotion & -27.81 & 46.65 & -0.60 & 0.985 \\
Cognitive load $\times$ Emotion & -70.00 & 47.21 & -1.48 & 0.508 \\
Language $\times$ Cognitive load $\times$ Emotion & 45.44 & 66.62 & 0.68 & 0.970 \\
Random effects & & & & \\
Participants & 112.88 & 106.25 & & \\
Words & 79.44 & 89.13 & & \\
\hline
\end{tabular}




\section{Table D3}

Model Parameters for the Best-fitting Generalized Linear Mixed Model on Gambling Ratio in the Gambling Task.

$\beta \quad S E \frac{\text { Contrast }}{2}$

Fixed effects

\begin{tabular}{lcccc} 
Intercept & 2.00 & 0.54 & 3.69 & $<0.002^{* * *}$ \\
Language & 0.11 & 0.22 & 0.50 & 0.996 \\
Cognitive load & -0.06 & 0.23 & -0.26 & 0.999 \\
Emotion & 0.08 & 0.21 & 0.38 & 0.999 \\
Language $\times$ Cognitive load & 0.31 & 0.32 & 0.98 & 0.867 \\
Language $\times$ Emotion & -0.41 & 0.30 & -1.37 & 0.610 \\
Cognitive load $\times$ Emotion & 0.03 & 0.32 & 0.11 & 1.000 \\
Language $\times$ Cognitive load $\times$ Emotion & 0.19 & 0.43 & 0.44 & 0.998 \\
Random effects & & & & \\
Participants & 3.56 & 1.89 & & \\
Potential gain/loss & 3.53 & 1.88 & & \\
\hline
\end{tabular}




\section{Table D4}

Model Parameters for the Best-fitting Generalized Linear Mixed Model on Reaction Times in the Gambling Task.

$\beta \quad S E \frac{\text { Contrast }}{2}$

Fixed effects

\begin{tabular}{lcccc} 
Intercept & 767.41 & 32.91 & 23.32 & $<0.001^{* * * *}$ \\
Language & 6.50 & 18.01 & 0.36 & 0.999 \\
Cognitive load & 15.55 & 19.59 & 0.79 & 0.946 \\
Emotion & -15.09 & 18.04 & -0.84 & 0.931 \\
Language $\times$ Cognitive load & -24.60 & 26.26 & -0.94 & 0.889 \\
Language $\times$ Emotion & 15.19 & 25.20 & 0.60 & 0.987 \\
Cognitive load $\times$ Emotion & 17.57 & 27.28 & 0.64 & 0.981 \\
Language $\times$ Cognitive load $\times$ Emotion & 2.77 & 35.94 & 0.08 & 1.000 \\
Random effects & & & & \\
Participants & 22.93 & 15.42 & & \\
Potential gain/loss & 25.55 & 50.55 & & \\
\hline
\end{tabular}




\section{Appendix E. Functional Connectivity (PPI)}

\section{Table 1}

Brain Activations Elicited in the High-load vs. Low-load and Negative vs. Neutral Contrast in L1 and L2 Conditions (L1: GRF Correction - Voxel p value $=.001$, Cluster $p$ value $=.05 ;$ L2: $p=.005$, Uncorrected $)$.

\begin{tabular}{|c|c|c|c|c|c|c|}
\hline \multirow{2}{*}{$\begin{array}{l}\text { Region } \\
\text { High-load > Low-loac } \\
\text { L1 Neg }\end{array}$} & \multirow[t]{2}{*}{ Hemisphere } & \multirow[t]{2}{*}{$\begin{array}{l}\text { Cluster size } \\
\text { (voxels) }\end{array}$} & \multicolumn{3}{|c|}{$\begin{array}{l}\text { Peak } \\
\text { Coordinates } \\
\text { MNI }(\mathrm{x}, \mathrm{y}, \mathrm{z})\end{array}$} & \multirow[t]{2}{*}{$\begin{array}{l}\text { Peak } \\
\text { intensity ( } \mathrm{T} \\
\text { value) }\end{array}$} \\
\hline & & & & & & \\
\hline Dorsal striatum & $\mathrm{R}$ & 53 & 27 & 12 & 3 & 5.0709 \\
\hline Amygdala & $\mathrm{L}$ & 13 & -27 & 3 & -24 & 6.5187 \\
\hline \multicolumn{7}{|l|}{ none } \\
\hline \multicolumn{7}{|l|}{ L2 Neg } \\
\hline Dorsal striatum & $\mathrm{R}$ & 16 & 15 & -6 & 3 & 4.0877 \\
\hline Frontal_Inf_Orb & $\mathrm{L}$ & 7 & -36 & 36 & -15 & 3.5513 \\
\hline Insula & $\mathrm{L}$ & 6 & -39 & 15 & -3 & 3.3936 \\
\hline $\begin{array}{l}\text { Middle Frontal Gyrus } \\
\text { L2 Neu }\end{array}$ & $\mathrm{L}$ & 22 & -39 & 27 & 33 & 3.8676 \\
\hline Parahippocampal & $\mathrm{R}$ & 5 & 33 & -36 & -12 & 3.8625 \\
\hline Insula & $\mathrm{L}$ & 5 & -45 & 9 & 6 & 4.3357 \\
\hline \multicolumn{7}{|l|}{ Negative $>$ Neutral } \\
\hline $\begin{array}{l}\text { L1 low-load } \\
\text { None }\end{array}$ & \multicolumn{5}{|c|}{ L1 low-load } & \\
\hline \multicolumn{7}{|l|}{ L1 high-load } \\
\hline Insula & $\mathrm{R}$ & 12 & 30 & 24 & -18 & 5.3164 \\
\hline \multicolumn{7}{|l|}{ L2 low-load } \\
\hline Fusiform & $\mathrm{R}$ & 8 & 36 & -57 & -9 & 4.4937 \\
\hline \multicolumn{7}{|l|}{ Gyrus } \\
\hline \multicolumn{7}{|l|}{ L2 high-load } \\
\hline Middle Frontal Gyrus & $\mathrm{L}$ & 20 & -42 & 30 & 33 & 4.3089 \\
\hline
\end{tabular}

